\title{
Hydrogen peroxide route to Sn-doped titania photocatalysts
}

Václav Šteng ${ }^{1,2^{*}}$, Tomáš Matys Grygar ${ }^{1,2}$, Jiř́ Henych ${ }^{1,2}$ and Martin Kormunda ${ }^{3}$

\begin{abstract}
Background: The work aims at improving photocatalytic activity of titania under Vis light irradiation using modification by Sn ions and an original, simple synthesis method. Tin-doped titania catalysts were prepared by thermal hydrolysis of aqueous solutions of titanium peroxo-complexes in the presence of $\mathrm{SnCl}_{4}$ or $\mathrm{SnCl}_{2}$ using an original, proprietary "one pot" synthesis not employing organic solvents, metallo-organic precursors, autoclave aging nor post-synthesis calcination. The products were characterized in details by powder diffraction, XPS, UV-Vis, IR, and Raman spectroscopies, electron microscopy and surface area and porosity measurements

Results: The presence of tin in synthesis mixtures favors the formation of rutile and brookite at the expense of anatase, decreases the particle size of all formed titania polymorphs, and extends light absorption of titania to visible light region $>400 \mathrm{~nm}$ by both red shift of the absorption edge and introduction of new chromophores. The photocatalytic activity of titania under UV irradiation and $>400 \mathrm{~nm}$ light was tested by decomposition kinetics of Orange II dye in aqueous solution

Conclusions: Doping by Sn improves titania photoactivity under UV light and affords considerable photoactivity under $>400 \mathrm{~nm}$ light due to increased specific surface area and a phase heterogeneity of the Sn-doped titania powders.
\end{abstract}

Keywords: $\mathrm{TiO}_{2}$, Sn doping, Wet synthesis, Vis light, Photocatalysis

\section{Background}

In the last two decades researchers have systematically tried to improve performance of titania photocatalysts and make its synthesis simpler and more robust. Increasing titania efficiency under visible light activation has been one of the most desired improvements. There are several ways to achieve this goal, of which about the most powerful is titania modification by other elements, such as Sn. Perhaps a seminal work on this topic was published in 1995 by Vinodgopal and Kamat [1], who observed that UV-activated degradation of an azo dye by a physical mixture of $\mathrm{SnO}_{2}$ and $\mathrm{TiO}_{2}$ is by nearly an order of magnitude faster than with pure oxide components and attributed this effect to the existence of physical contacts between the two semiconductors. Similarly

\footnotetext{
* Correspondence: stengl@iic.cas.cz

'Department of Solid State Chemistry and Analytical Laboratory, Institute of Inorganic Chemistry AS CR v.vi.., 250 68, Řež, Czech Republic

${ }^{2}$ Faculty of the Environment, J.E. Purkyně University, Králova Výšina 7, 400 96, Ústí nad Labem, Czech Republic

Full list of author information is available at the end of the article
}

substantial, nearly tenfold increase in the rate of UVactivated degradation of acetone (with respect to pure rutile) was reported with Sn-doped rutile by Lin et al. [2], but they stated explicitly that the presence of segregated $\mathrm{SnO}_{2}$ has a detrimental effect on the catalysis. Those studies have been followed by many other researchers; they mostly revealed that the titania lattice substitution by $\mathrm{Sn}$ improves both rutile [2,3] and anatase photocatalytic performances $[4,5]$. Observation that Sn-doping considerably improves photodegradation under visible light has become a further substantial step forward [3-6].

The positive effect of Sn on titania catalytic efficiency was attributed to a change of the anatase electronic structure - decrease of band gap (shift of absorption edge toward visible light area), and introduction of specific Sn-related surface sites was also mentioned $[3,4,6]$. Actually the studies on Sn-modification of titania discussed hypotheses that it can introduce heterojunctions improving a charge-hole separation [1], increase photo-excited electron-hole lifetime within a single particle [2] alter the electronic structure of the metal oxide photocatalysts $[3,4,6]$
() Chemistry Central

(c) 2012 Štengl et al.; licensee Chemistry Central Ltd. This is an Open Access article distributed under the terms of the Creative Commons Attribution License (http://creativecommons.org/licenses/by/2.0), which permits unrestricted use, distribution, and reproduction in any medium, provided the original work is properly cited. 
increase the particle size $[2,3,7,8]$ and porosity [6], and control the actually developed crystal facets [9]. The authors of practically each study have developed their own interpretation of the positive effect of Sn - obviously the Sn doping effect is neither satisfactorily understood nor unequivocally experimentally described.

This work reports on a proprietary synthesis procedure to Sn-doped titania photocatalysts developed by Štengl and co-workers [10-12] in aim to allow their possible future industrial production. With the same motivation, we have recently developed an "urea route" $[13,14]$. The UV photocatalytic efficiency of the titania formed by the "urea route" [15] is substantially improved by chemical modifications [16-18]; currently this route is used in production of commercially available photoactive paint (ww.detoxycolor.cz/en/). Contrarily to that "one pot" syntheses, majority of previously published synthesis routes to titania photocatalysts are multi-step processes employing metal alkoxides as raw materials, non-aqueous solvents, and/or including crystallization step after chemical synthesis of precursors. The use of rather complex synthesis protocols can be substantiated in making thin films [4,5] or building nanoarchitectures [19], but it seems needless for the production of powders. There are indeed several synthesis ways to catalytically efficient titania powders without a need of metallo-organic compounds and organic solvents, but they usually require separate thermal [20] or hydrothermal crystallization steps [7-9] applied to poorly crystalline or amorphous intermediates from wet synthesis. In this paper, we reported on a "one-pot" thermal hydrolysis of titanium peroxo-complexes in the presence of $\mathrm{Sn}$ (II) or $\mathrm{Sn}$ (IV) chloride in aqueous solution. That "hydrogen peroxide route" is based on hydrolysis of $\mathrm{Ti}(\mathrm{IV})$ sulfate, treatment of the resulting gel by hydrogen peroxide, and thermal decomposition of so formed peroxo-titanate under reflux at ambient pressure producing directly the photocatalyst $[10,11,18]$. The resulting powders were tested in photobleaching of Orange II dye in aqueous slurry under irradiation at wavelengths of $365 \mathrm{~nm}$ and $>400 \mathrm{~nm}$ using a home-made reactor [21]. The decomposition of soluble dyes [22] belongs now among the most widely used proxy methods (simple quantitative tests) to study titania photocatalysts, although its scientific value has recently been criticized [23]. In comparison with previously prepared photocatalytic materials based on $\mathrm{TiO}_{2}$ modified by molybdenum [11], iodine [17], or tungsten [18], the tin-doped titanium oxides exhibit a promising photocatalytic activity under activation by light $>400 \mathrm{~nm}$.

\section{Results and discussions}

Rutile and cassiterite have the same crystal structure with space group of $\mathrm{P} 4 / \mathrm{mnm}$. $\mathrm{SnCl}_{4}$ and $\mathrm{SnCl}_{2} \cdot 2 \mathrm{H}_{2} \mathrm{O}$ during the thermal hydrolysis of titania peroxo-compounds also works as a mineralizers similarly as in hydrothermal synthesis $[24,25]$. The mineralizers are adsorbed on the surface of crystallites and if the adsorption has selectivity to crystal facets, they control the final morphology of crystallites [26]. If the adsorption has no selectivity, the adsorbed additives on the surface may retard the deposition of the product component to decrease the growth rate and consequently the reduction of the particle size. For example, rutile $\mathrm{TiO}_{2}$ can be formed with the addition of a rutile-directing mineralizer such as $\mathrm{SnCl}_{2}, \mathrm{SnCl}_{4}$, $\mathrm{NH}_{4} \mathrm{Cl}, \mathrm{NaCl}$ or $\mathrm{SnO}_{2}$ [27,28], presence of some carboxylic acids or $\mathrm{SO}_{4}^{2-}$ promotes anatase crystallization $[29,30]$ and $\mathrm{HNO}_{3}, \mathrm{AlCl}_{3} \cdot 6 \mathrm{H}_{2} \mathrm{O}, \alpha-\mathrm{Al}_{2} \mathrm{O}_{3}, \mathrm{Al}(\mathrm{OH})_{3}$ and glycolic acid favor brookite formation [31,32]. $\mathrm{SnO}_{2}$ has same crystal structure with $\mathrm{TiO}_{2}$ rutile, therefore it was easily formed and adsorbed on the surface of $\mathrm{TiO}_{2}$ to retard the growth of $\mathrm{TiO}_{2}$ particles and enhance new nucleation. $\mathrm{TiO}_{2}$ in rutile form was achieved in the as precipitated stage by the addition of $\mathrm{SnO}_{2}$ as rutile forming nuclei and the amount of $\mathrm{SnO}_{2}$ directly influences the structure of resulting powders [33].

\section{Phase composition of catalysts}

The XRD patterns of prepared Sn-doped titanium oxides are presented in Figures 1 and 2. A mixture of titania polymorphs containing anatase (ICDD PDF 21-1272), rutile (ICDD 21-1276), and/or brookite (ICDD 291360) were found in oxides obtained from mixtures with $\mathrm{Sn}$ ions, while only anatase was found at the lowest $\mathrm{SnCl}_{2}$ addition and only rutile at higher $\mathrm{Sn}$ addition. No diffraction lines of cassiterite $\left(\mathrm{SnO}_{2}\right)$ were detected. The crystallite size and phase composition are listed in Tables 1 and 2. The cell parameters $a$ and $c$ of anatase and rutile and $a, b$ and $c$ of brookite were calculated by the Rietveld refinement and presented in Additional file 1: Tables S1 and S2. The products contain more rutile at lower $\mathrm{Sn}$ percentages if $\mathrm{SnCl}_{4}$ was used. These results are consistent with the rutile-promoting effect of $\mathrm{Sn}$ observed in wet synthesis [6] and wet synthesis followed by thermal [2,3] or hydrothermal [8] crystallization. Interestingly, hydrothermal (autoclave) recrystallization of wet synthesized mixed Ti-Sn precursors usually produced Sn-doped anatase [5,7]. Brookite formation in the absence of "phase-directing agents", chloride ions and strong acids is not common ([34] and references there).

With increasing amount of $\mathrm{Sn}^{4+}$ there is a gradual diminishing of crystallites in all three phases (see Table 1). Concerned the structural properties, the very similar ionic radius of $\mathrm{Ti}^{4+}(0.605 \AA)$ [35] and $\mathrm{Sn}^{4+}$ $(0.690 \AA)$ [36] would allow easy substitution of $\mathrm{Ti}^{4+}$ by $\mathrm{Sn}^{4+}$ in the $\mathrm{TiO}_{2}$ lattice, in comparison to $\mathrm{Sn}^{2+}$ that is much larger, $1.22 \AA$ [37]. Therefore, $\mathrm{Sn}^{2+}$ can only occupy the interstitial sites in $\left[\mathrm{TiO}_{4}\right]$ and $\left[\mathrm{TiO}_{6}\right]$, resulting 


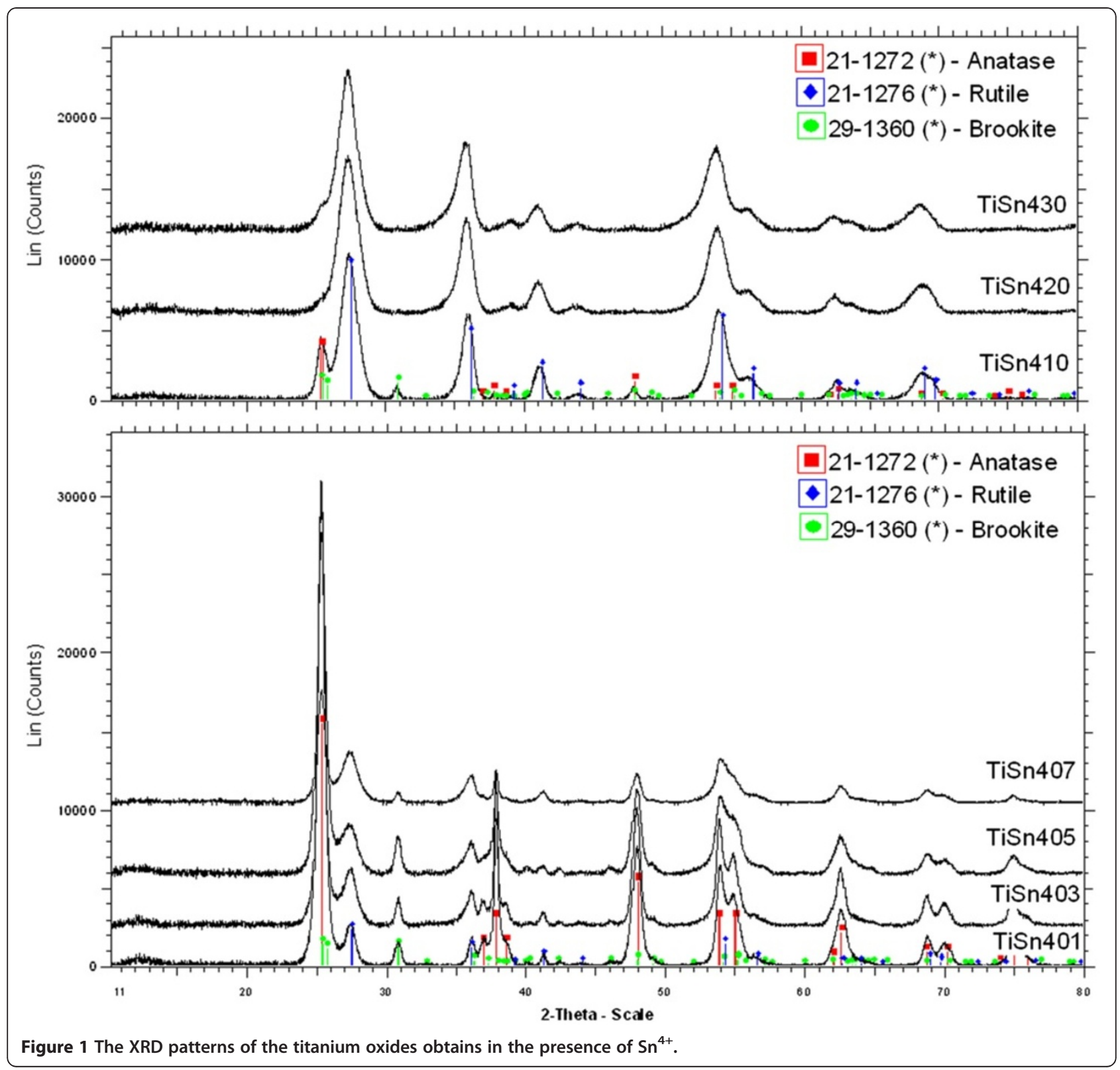

in a decrease in the lattice distortion energy, while $\mathrm{Sn}^{4+}$ can substitute for $\mathrm{Ti}^{4+}$ in $\left[\mathrm{TiO}_{4}\right]$ and $\left[\mathrm{TiO}_{6}\right]$, resulting in an increase in the distortion energy [38]. This paper supports those assumptions, the distortion of the lattice and increment the lattice parameters of $\mathrm{Sn}^{4+}$ doped $\mathrm{TiO}_{2}$ nanocrystals are demonstrated in Additional file 1: Table S2. The expansion of anatase, rutile and brookite cells attributes to the larger ionic radius of the doping $\mathrm{Sn}^{4+}$ ion than that of the lattice $\mathrm{Ti}^{4+}$ ion.

The phase composition obtained by XRD was confirmed by a Raman microanalysis. The Raman spectra of $\mathrm{Sn}^{4+}$ - and $\mathrm{Sn}^{2+}$-doped titanium oxides are presented in Figures 3 and 4. The Raman bands were assigned to phases using published data [39-41]. Rutile $\mathrm{TiO}_{2}$ shows four Raman-active fundamental modes at $143 \mathrm{~cm}^{-1}$ $\left(B_{1 \mathrm{~g}}\right), 447 \mathrm{~cm}^{-1}\left(\mathrm{E}_{\mathrm{g}}\right), 612 \mathrm{~cm}^{-1}\left(\mathrm{~A}_{1 \mathrm{~g}}\right)$, and $826 \mathrm{~cm}^{-1}\left(\mathrm{~B}_{2 \mathrm{~g}}\right)$ $[39,41]$ and brookite have complex of 17 characteristic bands at 127, 154, 194, 247, 412, $640 \mathrm{~cm}^{-1}\left(\mathrm{~A}_{1 \mathrm{~g}}\right), 133$, 159, 215, 320, 415, $502 \mathrm{~cm}^{-1}\left(\mathrm{~B}_{1 \mathrm{~g}}\right), 366,395,463$, $584 \mathrm{~cm}^{-1}\left(\mathrm{~B}_{2 \mathrm{~g}}\right)$ and $452 \mathrm{~cm}^{-1}\left(\mathrm{~B}_{3 \mathrm{~g}}\right)$ [40] of which only the most intense ones were registered. The specific vibration modes are located at $145 \mathrm{~cm}^{-1}\left(\mathrm{E}_{\mathrm{g}}\right), 199 \mathrm{~cm}^{-1}\left(\mathrm{E}_{\mathrm{g}}\right)$, $399 \mathrm{~cm}^{-1}\left(\mathrm{~B}_{1 \mathrm{~g}}\right), 515 \mathrm{~cm}^{-1}\left(\mathrm{~B}_{1 \mathrm{~g}}+\mathrm{A}_{1 \mathrm{~g}}\right)$ and $638 \mathrm{~cm}^{-1}\left(\mathrm{E}_{\mathrm{g}}\right)$ indicating the presence of the anatase phase in samples denoted TiSn401, TiSn403, TiSn405 and TiSn407 [42]. The Raman band at 246, 321 and $364 \mathrm{~cm}^{-1}$ correspond with brookite phase and band at $448 \mathrm{~cm}^{-1}$ can be assigned to rutile. The samples TiSn401, TiSn402 and 


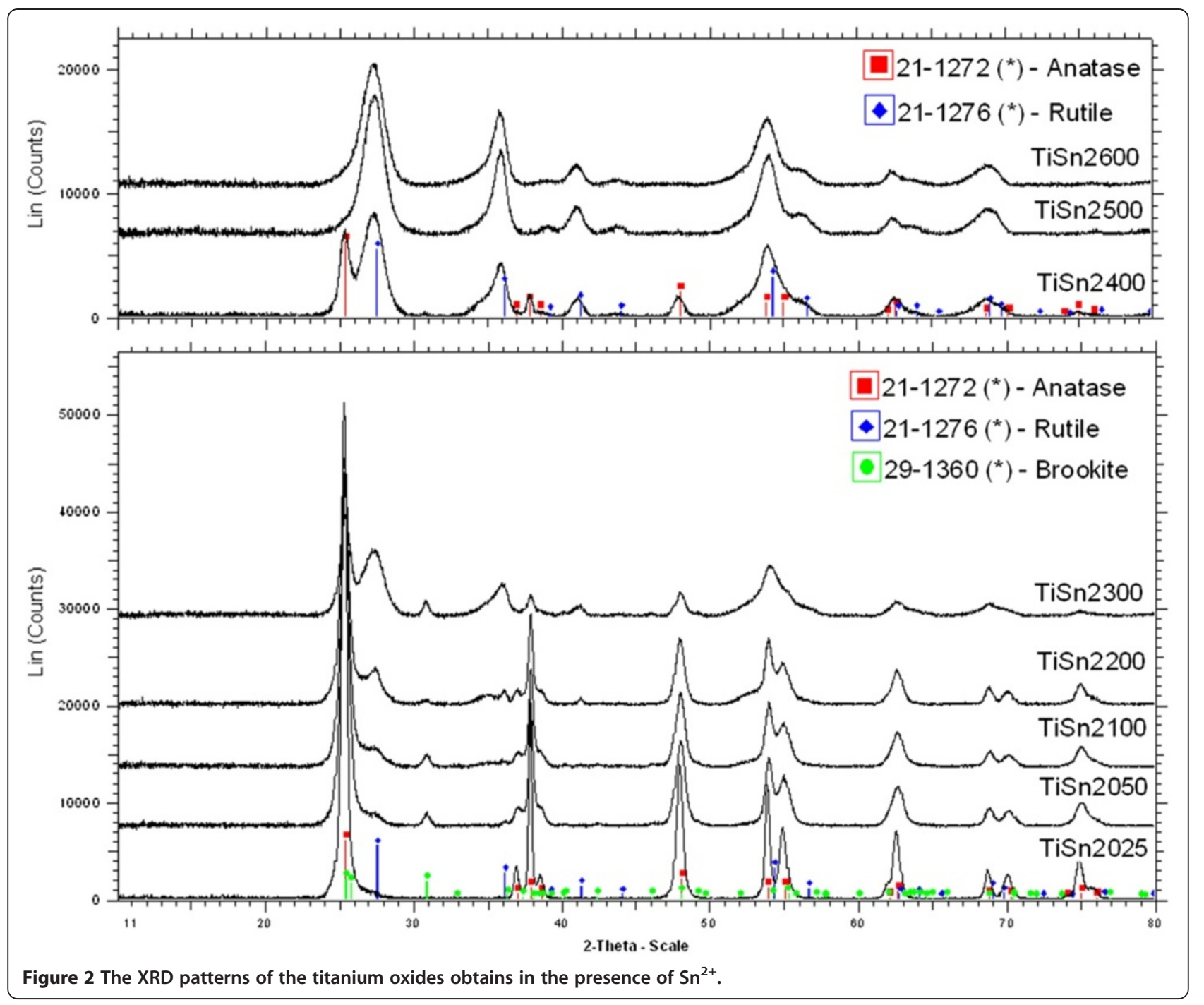

TiSn403 can be assigned to three of the four Raman rutile bands, namely at $147 \mathrm{~cm}^{-1}\left(\mathrm{~B}_{1 \mathrm{~g}}\right), 440 \mathrm{~cm}^{-1}\left(\mathrm{E}_{\mathrm{g}}\right)$ and $612 \mathrm{~cm}^{-1}\left(\mathrm{~A}_{1 \mathrm{~g}}\right)$. The series samples of $\mathrm{Sn}^{2+}$ doped $\mathrm{TiO}_{2}$ (see Figure 4) can be assigned to anatase (TiSn2025, TiSn2050 and TiSn2100), a mixture of anatase and brookite (TiSn2200, TiS2300, TiSn2400) or to pure rutile to samples TiSn2500 and TiSn2600. Moreover, the main Raman bands at 490, 574, 636, and $776 \mathrm{~cm}^{-1}$ attributed to $\mathrm{SnO}_{2}$ crystalline form were not detected, which indicates that tin does not exist as a separate crystalline oxide phase [43]. These results are in good agreement with those from the XRD analysis.

The samples TiSn401, TiSn403, TiSn405 and TiSn407 showed Raman shift from 145.3 to $150.6 \mathrm{~cm}^{-1}$ due to incorporation of $\mathrm{Sn}^{4+}$ to titania matrix. The Raman shifts cannot be affected by decreasing anatase crystallites size [44], as is evident from Table 1 - the titania crystals are too coarse to produce phonon confinement. In the
TiSn2YY series the Raman band position of anatase is roughly constant with $\mathrm{a} \sim 147 \mathrm{~cm}^{-1}$.

A study by HRTEM with SAED was also consistent with the phase analysis. Diffraction line positions obtained by SAED are shifted to higher $d$ with respect to pure anatase consistently with the results of the XRD study due to an anatase cell size expansion.

The Raman microscopy revealed a considerable difference in the homogeneity of the photocatalysts in the two series $\left(\mathrm{SnCl}_{2}\right.$ and $\left.\mathrm{SnCl}_{4}\right)$ at a spatial scale of several $\mu \mathrm{m}$ (the spot size of the laser beam on the sample). The $\mathrm{SnCl}_{2}$ addition produced more uniform specimens, with only rare anatase-rich grains with a diameter $<10 \mu \mathrm{m}$ at higher Sn contents. The $\mathrm{SnCl}_{4}$ addition resulted in considerably more heterogeneous mixtures. TiSn403, TiSn405 and TiSn407 consist of an anatase matrix with small grains of an anatase-rutile mixture, while TiSn2050, TiSn2100 are quite homogeneous anatase-brookite mixtures at the $\mu \mathrm{m}$ scale. 
Table 1 Surface area, total pore volume, crystallite size and phase composition of $\mathrm{Sn}^{4+}$ series of $\mathrm{TiO}_{2}$

\begin{tabular}{lcccccccccc}
\hline Sample & $\begin{array}{c}\mathrm{SnCl}_{\mathbf{4}} \\
{[\mathbf{m l}]}\end{array}$ & $\begin{array}{c}\mathrm{Sn} \\
{[\mathbf{w t . \%}]}\end{array}$ & $\begin{array}{c}\text { Surface Area } \\
{\left[\mathbf{m}^{\mathbf{2}} \mathbf{g}^{-1}\right]}\end{array}$ & $\begin{array}{c}\text { Total Pore Volume } \\
{\left[\mathbf{c m}^{\left.\mathbf{3} \mathbf{g}^{-1}\right]}\right.}\end{array}$ & $\begin{array}{c}\text { Anatase } \\
\text { by XRD } \\
{[\%]}\end{array}$ & $\begin{array}{c}\text { Anatase } \\
\text { Cryst. Size } \\
{[\mathbf{n m}]}\end{array}$ & $\begin{array}{c}\text { Rutile by } \\
\text { RD [\%] }\end{array}$ & $\begin{array}{c}\text { Rutile Cryst. } \\
\text { Size [nm] }\end{array}$ & $\begin{array}{c}\text { Brookite } \\
\text { by XRD [\%] }\end{array}$ & $\begin{array}{c}\text { Brookite } \\
\text { Cryst. Size } \\
{[\mathbf{n m}]}\end{array}$ \\
\hline TiSn401 & 0.1 & 0.71 & 96.5 & 0.32 & 84.1 & 46.2 & 11.2 & 43.3 & 4.7 & 30.1 \\
TiSn403 & 0.3 & 1.03 & 101.5 & 0.33 & 75.5 & 47.8 & 18.5 & 25.7 & 6.0 & 47.0 \\
TiSn405 & 0.5 & 1.97 & 121.1 & 0.27 & 65.5 & 49.2 & 19.3 & 18.9 & 15.2 & 36.7 \\
TiSn407 & 0.7 & 3.45 & 140.0 & 0.32 & 46.1 & 32.5 & 50.4 & 16.1 & 3.5 & 34.4 \\
TiSn410 & 1.0 & 5.04 & 157.7 & 0.23 & 5.1 & - & 88.5 & 15.9 & 6.4 & 24.3 \\
TiSn420 & 2.0 & 9.30 & 194.6 & 0.20 & - & - & 100 & 15.6 & - & - \\
TiSn430 & 3.0 & 12.27 & 185.9 & 0.21 & - & - & 100 & 10.2 & - & - \\
\hline
\end{tabular}

TiSn430 with the highest $\mathrm{SnCl}_{4}$ loading has a pure rutile matrix with occasional small grains of an anatase-rich anatase-rutile mixture. The total content of anatase in nearly pure rutile specimens is too small to be detected in the XRD patterns. The reason why Raman spectroscopy detected it is its higher sensitivity to anatase than rutile and also a microscopic setup of Raman analysis. Consequently traces of anatase were also revealed in the TiSn2500 and TiSn2600, in both cases as a minor admixture in the rutile matrix.

XRD lattice parameters of anatase and rutile obtained by the "hydrogen peroxide route" are larger than stoichiometric anatase and rutile, particularly $a$ parameter of anatase and $a$ parameter of rutile are expanded. Such small but definite lattice expansion was also found in the non-doped anatase obtained from titanium sulfate by the urea hydrolysis $(a=3.786 \AA$ and $c=9.515 \AA,[16])$ as compared with pure anatase $(a=3.782 \AA$ and $c=9.502 \AA$, [45]). The non-stoichiometry could be attributed to a cation deficiency presumably due to $\mathrm{OH}^{-}$replacing $\mathrm{O}^{2-}$ excess of $\mathrm{O}$ ions (see the XPS results below).

Additional file 1: Figure S1 shows the IR spectrum of the $\mathrm{Sn}$-doped $\mathrm{TiO}_{2}$ prepared by thermal hydrolysis of titanium peroxo-complexes. The broad absorption peaks at about $3400 \mathrm{~cm}^{-1}$ and the band at $1625 \mathrm{~cm}^{-1}$ correspond to the surface adsorbed water and the hydroxyl groups [46]. The band at $1385 \mathrm{~cm}^{-1}$ can be assigned to adsorbed carbonates on surfaces of $\mathrm{TiO}_{2}$, formed probably by the adsorption of $\mathrm{CO}_{2}$ from air [47]. Surfaceadsorbed sulfate ions are probably responsible for a small band at $1100 \mathrm{~cm}^{-1}$ [48]. The peak located at $\sim 463 \mathrm{~cm}^{-1}$ in the FT-IR spectrum is likely due to the vibration of the Ti-O bond [49]. Since the $\mathrm{Ti}-\mathrm{O}$ bond is shorter than the $\mathrm{Sn}-\mathrm{O}$ bond, the doping of $\mathrm{Sn}^{4+}$ in $\mathrm{TiO}_{2}$ may lead to a shift of the lower wavenumber of $\mathrm{Ti}-\mathrm{O}$ lattice vibration [50].

Obviously the titania formed by the "hydrogen peroxide route" without a subsequent hydrothermal or thermal treatment is not perfectly stoichiometric. A minor additional expansion of the lattice size of the anatase and rutile in Sn-modified titania is observed with a growing Sn percentage. This result is consistent with the previously published findings $[2-4,8]$. This Sn-specific lattice expansion is attributed to a larger ionic radius of $\mathrm{Sn}^{4+}(0.690 \AA)$ than $\mathrm{Ti}^{4+}(0.605 \AA)$ [35,51]. The lattice parameters of $\mathrm{Sn}$-doped $\mathrm{TiO}_{2}$ nanocrystals are listed in Additional file 1: Table S2.

\section{XPS analysis}

The chemical state of metal ions in TiSn2100, TiSn2300, TiSn403 and TiSn410 was evaluated from the high resolution XPS spectra (see Figure 5) of O $1 \mathrm{~s}$, Sn 3d, C $1 \mathrm{~s}$ and Ti 2 p. Because the ratio peak areas/RSF for Sn $3 d$ and Ti $2 p$ for each spin (spin-orbit coupling components) state

Table 2 Surface area, total pore volume, crystallite size and phase composition of $\mathrm{Sn}^{2+}$ series of $\mathrm{TiO}_{2}$

\begin{tabular}{|c|c|c|c|c|c|c|c|c|c|c|}
\hline Sample & $\begin{array}{c}\mathrm{SnCl}_{2} \\
{[\mathrm{~g}]}\end{array}$ & $\begin{array}{l}\text { EDS Sn } \\
\text { [wt.\%] }\end{array}$ & $\begin{array}{c}\text { Surface } \\
\text { Area } \\
{\left[\mathrm{m}^{2} \mathrm{~g}^{-1}\right]}\end{array}$ & $\begin{array}{c}\text { Total Pore } \\
\text { Volume } \\
{\left[\mathrm{cm}^{3} \mathrm{~g}^{-1}\right]}\end{array}$ & $\begin{array}{c}\text { Anatase by } \\
\text { XRD [\%] }\end{array}$ & $\begin{array}{l}\text { Anatase Cryst. } \\
\text { Size }[\mathrm{nm}]\end{array}$ & $\begin{array}{l}\text { Rutile by } \\
\text { XRD [\%] }\end{array}$ & $\begin{array}{l}\text { Rutile Cryst. } \\
\text { Size [nm] }\end{array}$ & $\begin{array}{c}\text { Brookite by } \\
\text { XRD [\%] }\end{array}$ & $\begin{array}{l}\text { Brookite Cryst. } \\
\text { Size [nm] }\end{array}$ \\
\hline TiSn2025 & 0.25 & 1.0 & 128.9 & 0.59 & 100 & 49.0 & 0 & - & 0 & - \\
\hline TiSn2050 & 0.5 & 1.3 & 206.7 & 0.72 & 94.2 & 35.3 & 0.8 & - & 5.0 & 36.4 \\
\hline TiSn2100 & 1.0 & 3.6 & 158.8 & 0.51 & 91.2 & 35.0 & 3.8 & - & 5.0 & 35.8 \\
\hline TiSn2200 & 2.0 & 4.1 & 203.9 & 0.46 & 89.5 & 31.5 & 10.5 & 15.3 & 0 & - \\
\hline TiSn2300 & 3.0 & 8.3 & 254.6 & 0.44 & 42.5 & 29.6 & 50.2 & 17.3 & 7.3 & 34.6 \\
\hline TiSn2400 & 4.0 & 13.5 & 430.7 & 0.61 & 33.6 & 24.1 & 64.4 & 18.1 & 0 & - \\
\hline TiSn2500 & 5.0 & 18.1 & 366.9 & 0.37 & 0 & - & 100 & 19.8 & 0 & - \\
\hline TiSn2600 & 6.0 & 20.6 & 291.5 & 0.31 & 0 & - & 100 & 21.2 & 0 & - \\
\hline
\end{tabular}



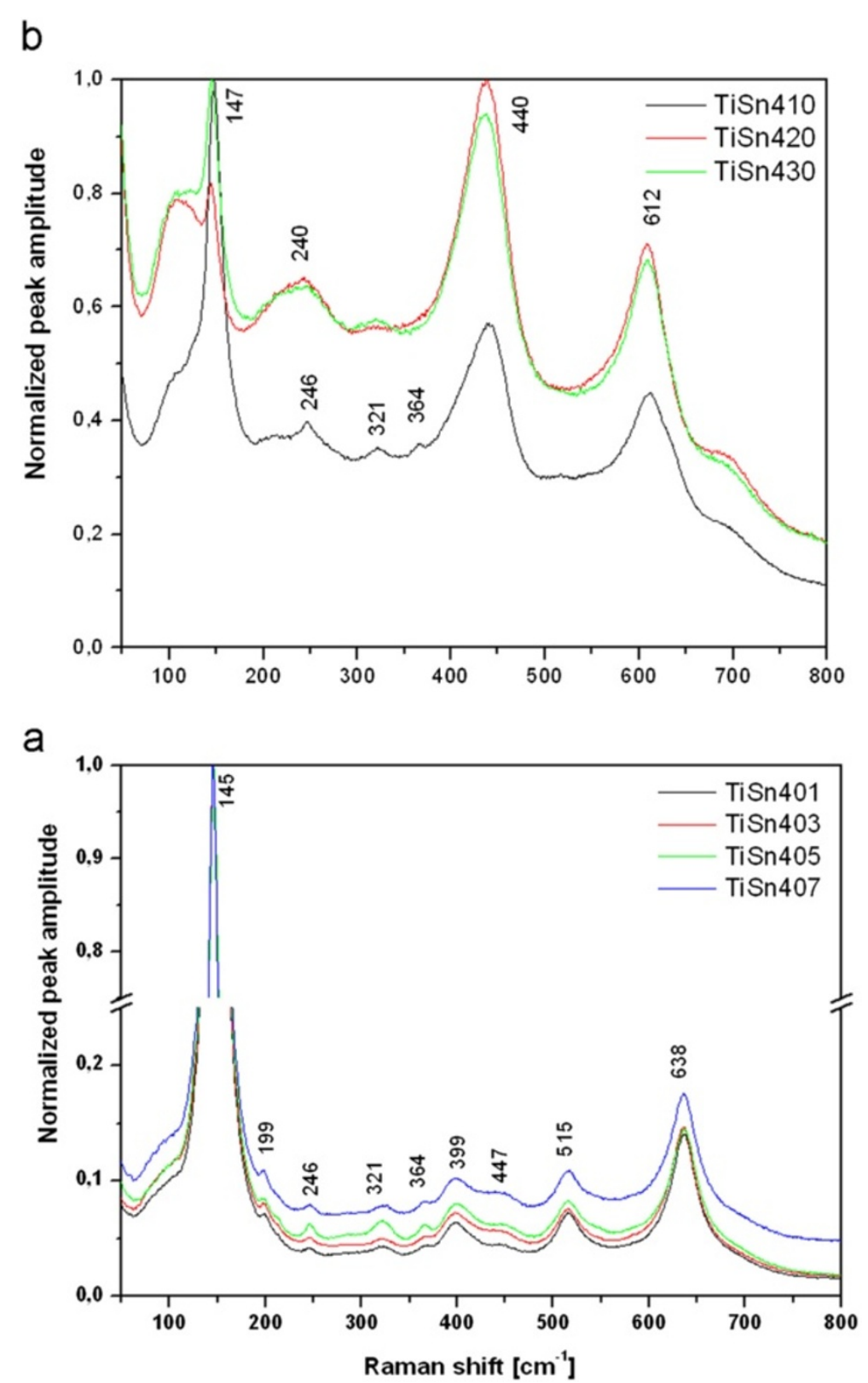

Figure 3 The Raman spectra of the titanium oxides obtained in the presence of $\mathrm{Sn}^{4+}$.

were giving a little different concentrations $\mathrm{Ti}_{1-\mathrm{x}}(\mathrm{O}, \mathrm{OH})_{2}$ $(x>0)$ therefore the ratio of both areas/RSF were always averaged. The compositions are summarized in the Additional file 1: Table S3. The O/Ti ratio show high oxygen over-stoichiometry. The high $\mathrm{O} / \mathrm{Ti}$ ratio can partly be explained by the fact that the O1s spectra show a main peak at $530.3 \mathrm{eV}$ with a shoulder at $\sim 531.5 \mathrm{eV}$. The peak at $530.3 \mathrm{eV}$ is assigned to the lattice oxygen, while the shoulder at $531.5 \mathrm{eV}$ may be attributed to the oxygen in hydroxyl groups. These two distinct signals, denoted $\mathrm{O}_{\mathrm{L}}$ and $\mathrm{O}_{\mathrm{H}}$, were found in nearly equal concentrations in Sn-anatase obtained by hydrothermal synthesis [7] and in roughly $10 \%$ fraction of $\mathrm{O}_{\mathrm{H}}$ after wet synthesis [6]. Obviously (at least) the surface of these titania specimens is strongly hydroxylated. The $\mathrm{Sn} /(\mathrm{Sn}+\mathrm{Ti})$ ratios obtained by XPS (from the surface of the crystallites) and EDS (from the depth up to a few $\mu \mathrm{m}$ ) are not significantly different in 3 samples of 4 analyzed (Additional file 1: Table S3). The catalysts obtained by the "hydrogen peroxide route" are hence not substantially surface enriched in $\mathrm{Sn}$, as in most previous studies $[3,6,7]$.

The high resolution measurements were made on $\mathrm{Sn}$ $3 \mathrm{~d}$ and Ti $2 \mathrm{p}$ states. The Ti $2 \mathrm{p} 3 / 2$ and Ti $2 \mathrm{p} 1 / 2$ were identified at binding energies $459.0 \mathrm{eV}$ and at $472.4 \mathrm{eV}$ 


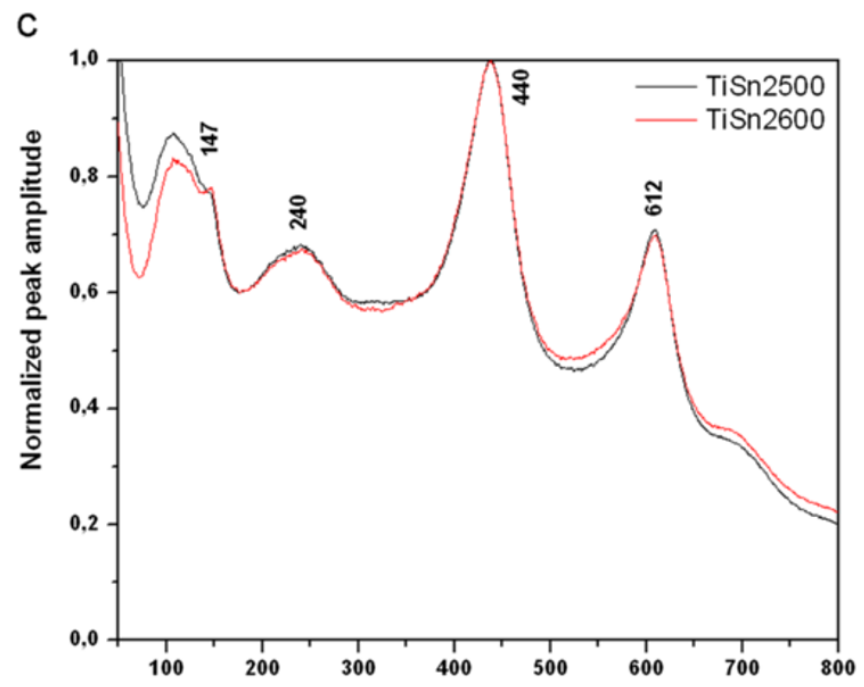

b

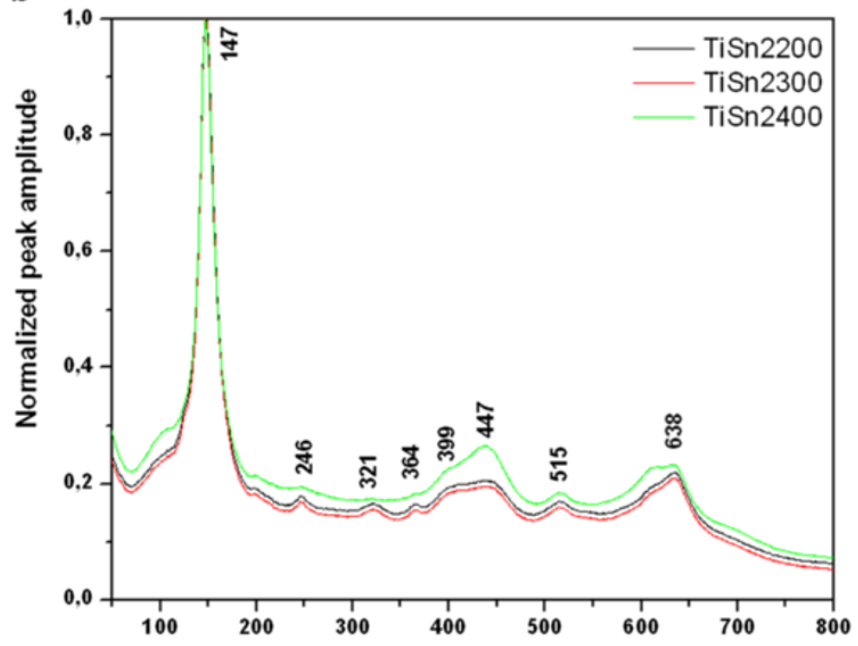

a

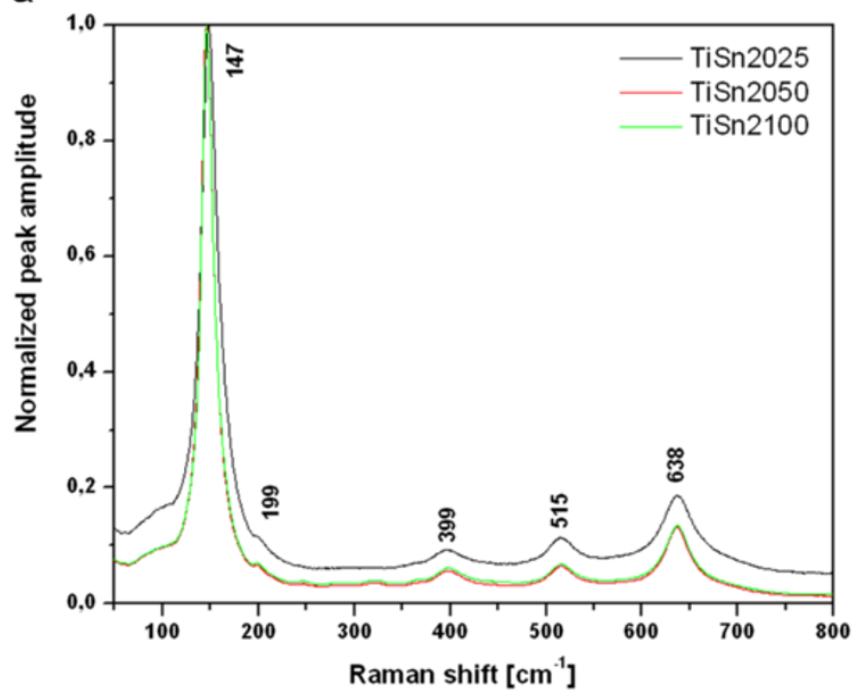

Figure 4 The Raman spectra of the titanium oxides obtained in the presence of $\mathrm{Sn}^{2+}$. 

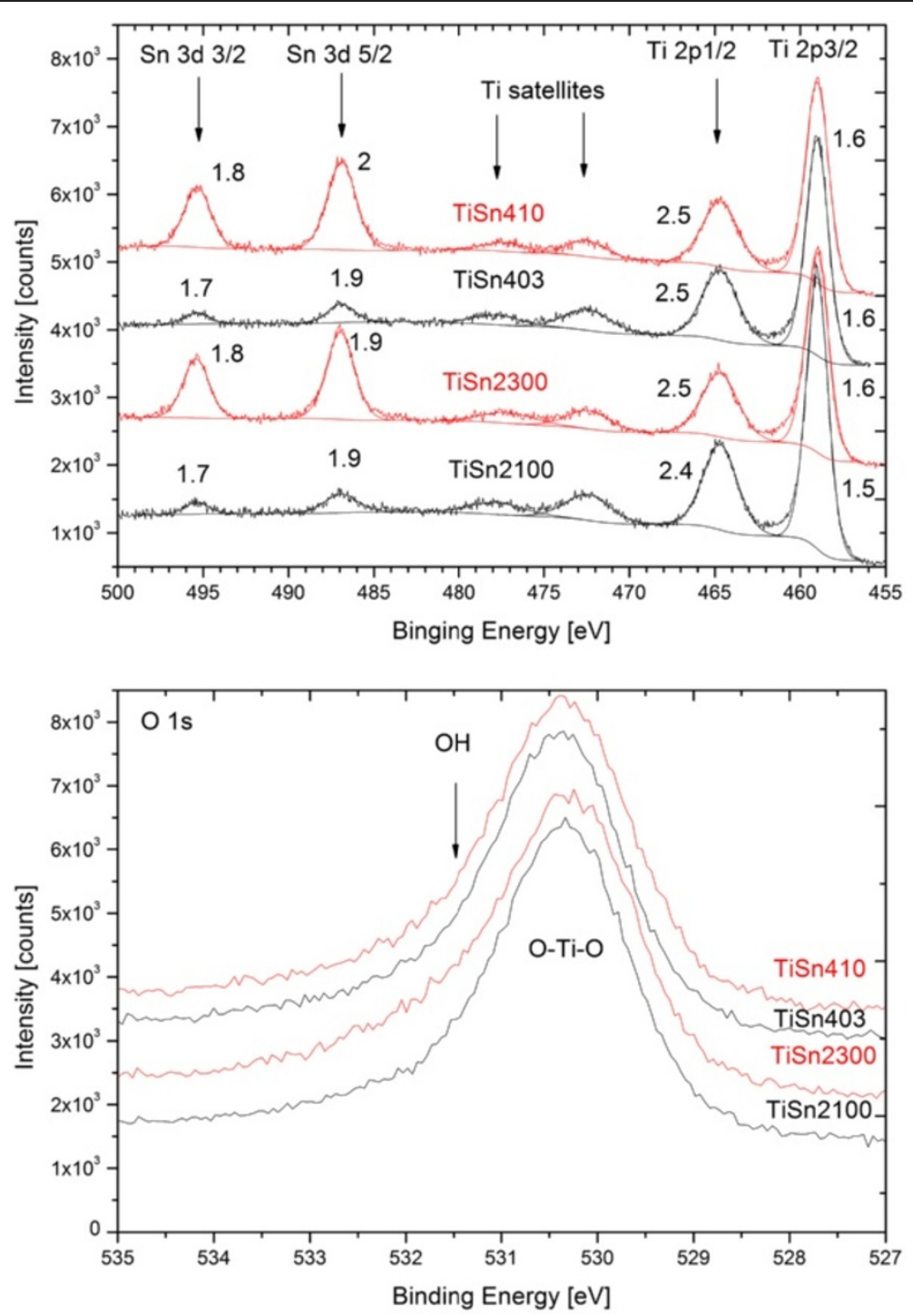

Figure 5 The selected regions from XPS spectra of Sn 3d, Ti 2p and O 1 s peaks on samples TiSn410, TiSn403, TiSn2300 and TiSn2100 with fitted peaks and indicated FWHM.

(472.3 eV in sample TiSn410). The Ti 2p3/2 state was used for the energy calibration in agreement with literature [52]. The control check was made on the binding energy of the $\mathrm{C} 1 \mathrm{~s}$ main component and the $\mathrm{C} 1 \mathrm{~s}$ was found at the binding energy about $285 \mathrm{eV}$, as expected for an ordinary surface contamination of samples handled under ambient conditions. The energy shifts due to the charging were similar to each other in all samples. The position of the $\mathrm{Ti} 2 \mathrm{p}$ peaks corresponds to the reported values and also the FWHM values about $1.6 \mathrm{eV}$ for $\mathrm{Ti} 2 \mathrm{p} 3 / 2$ and $2.5 \mathrm{eV}$ for $\mathrm{Ti} 2 \mathrm{p} 1 / 2$ are reasonable for single peak character, as is expected for $\mathrm{Ti}$ in $\mathrm{TiO}_{2}$. The control was made on the comparison of areas/RSF ratios for both spin states. The equal area/RFS ratios were found within precision about $10 \%$. The limited precision is due to the background removal by the Shirley background. The peak positions and FWHM were found to be practically identical for all investigated samples. The two additional peaks at binding energies approximately $472.4 \mathrm{eV}$ and approximately $477.8 \mathrm{eV}$ are commonly attributed to plasmons originating from the $\mathrm{Ti} 2 \mathrm{p}$ peaks. The plasmon features are in our case shifted towards higher binding energies by $13.4 \mathrm{eV}$ and $13.1 \mathrm{eV}$ respectively (the second one is shifted by only $12.5 \mathrm{eV}$ in the sample with a higher concentration of $\mathrm{Sn}$ ) are known satellites from $\mathrm{Ti} 2 \mathrm{p}$ and they are connected to the existence of plasmons.

The satellites at the binding energy about $477.1 \mathrm{eV}$ on the oxides with higher $\mathrm{Sn}$ contents are a bit closer to the main peak $(12.5 \mathrm{eV})$ than reported in literature. It can 
influence the properties connected to the plasmons. The area of those satellites is about $20 \%$ of the main corresponding Ti peaks, which is close to $24 \%$ or $25 \%$ reported in literature [52]. The second satellite peaks were also reported with the binding energy shifts about $25.4 \mathrm{eV}$ and $25.0 \mathrm{eV}$ for Ti $2 \mathrm{p} 3 / 2$ and Ti $2 \mathrm{p} 1 / 2$, respectively [52]. The tin related peaks Sn 3d3/2 at 495.4 eV and Sn 3d5/2 at $486.7 \mathrm{eV}$ were found in all samples and the corresponding FWHM were also practically identical.

Regretfully, the available literature values of binding energies of the $\mathrm{Sn} 3 \mathrm{~d} 5 / 2$ core levels for $\mathrm{SnO}(\mathrm{Eb}=487.1 \mathrm{eV}$ [53], 487.4 eV [54]) and $\mathrm{SnO}_{2}(\mathrm{~Eb}=487.01 \mathrm{eV}$ [55], $486.8 \mathrm{eV}$ [56]) nearly coincide, which made it hardly possible to differentiate between $\mathrm{SnO}$ and $\mathrm{SnO}_{2}$. On the other hand, in the above mentioned literature when the set of similar samples with $\mathrm{SnO}$ or $\mathrm{SnO}_{2}$ was measured and evaluated collectively, the differences between both states were clearly visible. The $\mathrm{SnO}_{2}$ should have a higher binding energy than $\mathrm{SnO}$ by about $0.5 \mathrm{eV}$ and hence in the $\mathrm{SnO}+\mathrm{SnO}_{2}$ mixtures the peak should be relatively broad [57]. This broadening has to be observed in both spin states of Sn 3d peaks. These peaks in all samples have clearly single peak character with FWHM $<2 \mathrm{eV}$. It is, of course, possible to use two components for such deconvolution, but then the FWHM would not be realistic - they would be either too narrow or one of the peaks would have only a very small area. Therefore the presence of mainly more stable $\mathrm{SnO}_{2}$ in the samples is most probable, while $\mathrm{SnO}$ phase can still be present in concentrations by an order of magnitude lower. Additionally, the small broadening of the peaks on the lower binding energy side can also be caused by the second satellite peak of $\mathrm{Ti} 2 \mathrm{p}$ [52] expected at binding energy about $484 \mathrm{eV}$ or background subtraction process or finally by a signal noise. This evaluation is in agreement with the expectation that $\mathrm{Sn}^{2+}$ should be quickly oxidized during the synthesis and subsequent sample handling in air.

The control check was made by the comparison of areas/RSF for both spin-orbit coupling components and the area/RSF ratios were found the same with relative deviations below $7 \%$ for samples TiSn 410 and TiSn2300 with higher Sn concentrations. The other specimens with low Sn concentrations have a poor agreement between the area/RSF ratios and the relative deviations were about $16 \%$ for sample TiSn 403 and $29 \%$ for sample TiSn2100. The poor precisions here are probably due to the background removal process from these noisy spectra. All the binding energies and FWHM values are summarized in Additional file 1: Table S4.

\section{Particle size and shape, porosity}

With increasing amount of $\mathrm{Sn}^{4+}$ there is a gradual decrease of a mean coherence length in all three titania phases as well as an increase of the total specific surface areas (see Table 1), which indicates that $S n$ presence decreases the growth rate of titanium oxide crystals. That inhibiting effect of Sn on the titania crystal growth is well known $[2,3,7,8]$. More interesting is that with increasing amount $\mathrm{Sn}^{4+}$ and $\mathrm{Sn}^{2+}$ there is a change of the pore size distribution: pores from the range of 10 $20 \mathrm{~nm}$ gradually shifts to the size between mesopores and micropores $(\sim 3 \mathrm{~nm})$. The Barrett-Joyner-Halenda $(\mathrm{BJH})$ pore-size distribution plot and nitrogen adsorption/desorption isotherms of as-prepared Sn-doped $\mathrm{TiO}_{2}$ are shown in Additional file 1: Figures S2 and S3. All samples have a type IV isotherm, which is characteristic of large-pore mesoporous material with a $\mathrm{H} 2$ type hysteresis. The high steepness of the hysteresis indicates a high order of mesoporosity. All samples are characteristic of Type A hysteresis loop according to de Boer's characterization [58] attributed to capillary pores - tubes open at both ends, wide ink-bottle pores and wedgeshaped capillaries.

TEM images of Sn-doped titanium oxide crystals are shown in Figures 6 and 7. The interlayer spacing $d \sim 0.34-0.36 \mathrm{~nm}$ in micrographs of Sn401, Sn405 and Sn420 can be assigned to crystal plane (101) of anatase or (120) of brookite (Figures 6a, b, e), interlayer spacings $d=0.342$ and $0.346 \mathrm{~nm}$ in micrographs Sn407, Sn410 (Figures 6c, d) evidently correspond to crystal planes (111) of brookite. The samples Sn420 and Sn430 have interlayer spacing $d \sim 0.32-0.33 \mathrm{~nm}$, which are from crystal planes (100) of rutile (Figures 6e, f). The crystal planes $d_{002}=0.49 \mathrm{~nm}$ in sample TiSn401 (Figure 6a) indicate a change in the anatase crystal morphology, as can be seen in Figure 8 .

The interlayer spacing shown in Figures 7a, b, c have $d$ in the range $0.346-0.360 \mathrm{~nm}$ and corresponds to crystal planes (101) anatase or (120) of brookite. The presence of lattice spacing $d_{100}=0.38 \mathrm{~nm}$ for the (100) anatase plane in TiSn2300 and TiSn2100 (Figures 7b, d) may indicate the occurrence of (010) anatase plane that is perpendicular to the [010] direction [59]. The incorporation of Sn to titania leads to an increase in the area of (010) surfaces at the expense of (101) and (10-1) and thus changes the morphology of the anatase crystal similarly as incorporation of W [17]. The interlayer spacing $\sim 0.331 \mathrm{~nm}$ corresponds to crystal surfaces (100) of rutile (Figure $7 \mathrm{f}$ ). Changes of the anatase crystal morphology resulting in increasing crystal plane (010) are shown in Figure 8. The selected area electron diffraction patterns (SAED), presented in Additional file 1: Figures S4 and S5, were analyzed by the Process Diffraction program that confirmed the structure composition results from XRD analysis. The Sn doping hence affects the formation of new crystal planes, which allow origin of next crystal facets, leading to a change in morphology 

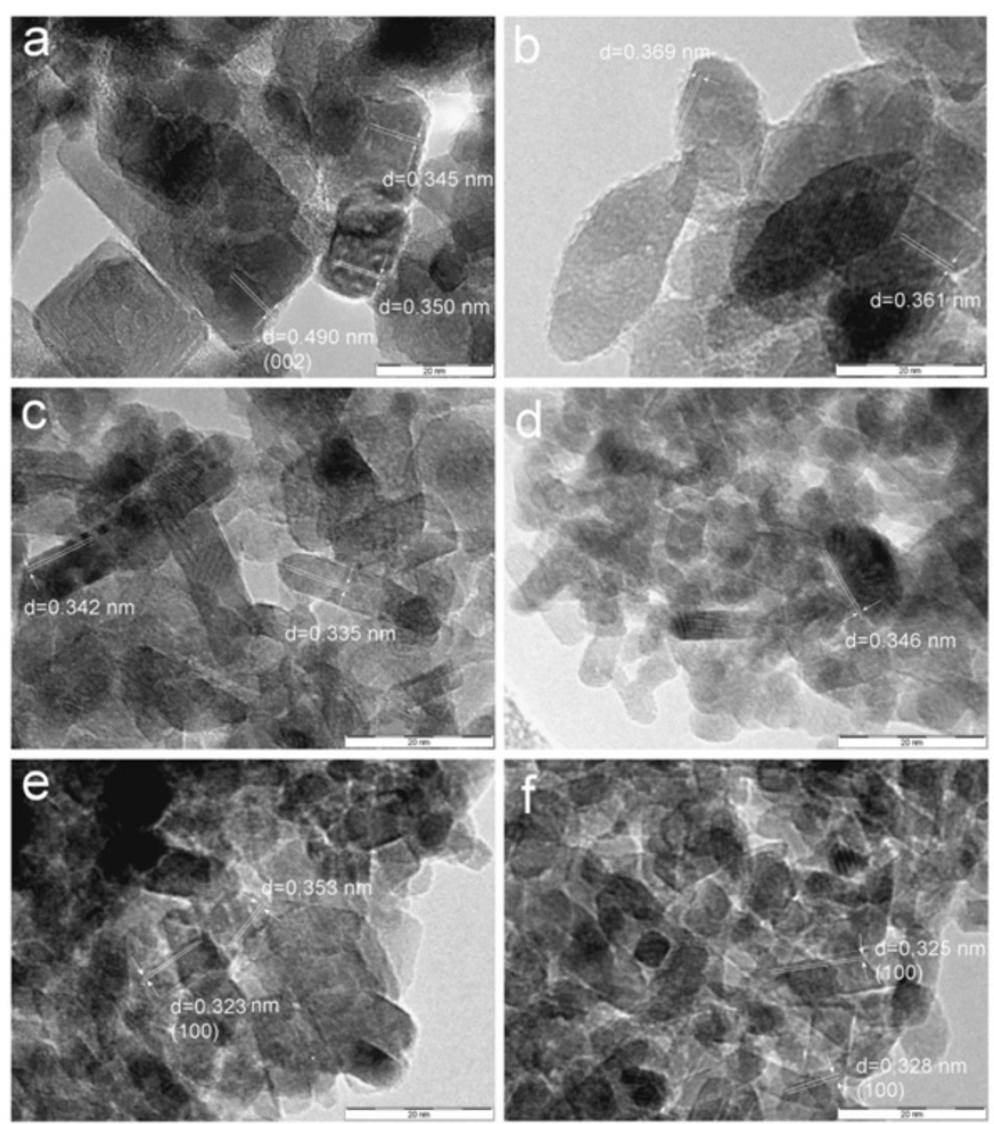

Figure 6 The TEM images of $\mathrm{Sn}^{4+}$-doped titanium oxides: a) TiSn401, b) TiSn405, c) TiSn407, d) TiSn410, e) TiSn420 and f) TiSn430.

of anatase (Figure 8). The crystal habit, i.e., the actual crystal facets evolved, can markedly change the specific activity of the titania catalysts $[9,12,60-63]$.

\section{UV/Vis absorption spectra}

Additional file 1: Figure S6 presents UV/Vis absorption spectra of the as-prepared tin-doped photocatalysts. Compared with the non-doped titania, the absorption edge of the doped samples TiSn401, TiSn403, TiSn405, TiSn407 and TiSn410 are red-shifted. The largest shift was found for a sample TiSn410, of which absorption tail extends to $\sim 425 \mathrm{~nm}$ (Additional file 1: Figure S6a). Samples TiSn420 and TiSn430 have an adsorption edge corresponding to the rutile phase $(\sim 410 \mathrm{~nm})$. The photocatalysts in TiSn2YYY series are red-shifted proportionally to the tin concentration (see Additional file 1: Figure S6b). TiSn2YY at higher Sn loadings and all TiSn4XX have additionally measurable absorption (f $(\mathrm{R})=0.02-0.05$ Kubelka-Munk units) in green to red region $(>500 \mathrm{~nm}$ ). Both the red-shifted absorption edge and the novel bands in Vis could be responsible for the photoactivity under $>400 \mathrm{~nm}$ light. Also previous researchers found that Sn-doping in anatase shifts the absorption band edge to longer wavelengths $[3,6,7]$ and at higher loading it produces new bands absorbing roughly between 400 and $500 \mathrm{~nm}[3,5,6]$, probably as a consequence of formation of new electron levels of $\mathrm{Sn}$ ions in the titania band structure.

Additional file 1: Figure S7 shows the $(\mathrm{A} h v)^{2}$ versus photon energy for a direct band-gap transition. The value of $3.20 \mathrm{eV}$ is for un-doped titania denoted as TiSn000. The value of band-gap energy decreases with increasing Sn content. The band gap of bulk $\mathrm{SnO}_{2}$ is $2.6 \mathrm{eV}$, which corresponds to an absorption edge of $\sim 450 \mathrm{~nm}$. The sample denoted TiSn410 has the lowest $\mathrm{E}_{\mathrm{bg}}$, next samples TiSn 420 and TiSn430 with pure rutile phase have $E_{b g}$ corresponding to rutile and incorporation of $\mathrm{Sn}^{4+}$ ions apparently does not affect the $\mathrm{E}_{\mathrm{bg}}$. Conversely for samples obtained in the presence of $\mathrm{Sn}^{2+}$ ions there is an evident shift of $\mathrm{E}_{\mathrm{bg}}$ up to the value of $\sim 2.95 \mathrm{eV}$.

\section{Photobleaching of Orange II dye}

The photocatalytic activity of the titanium oxides was tested by photobleaching of $5 \mathrm{mmol}$ Orange II dye aqueous solutions under UV radiation at $365 \mathrm{~nm}$ (UV-A, "Black Light") and >400 nm ("Warm White" lamp by 

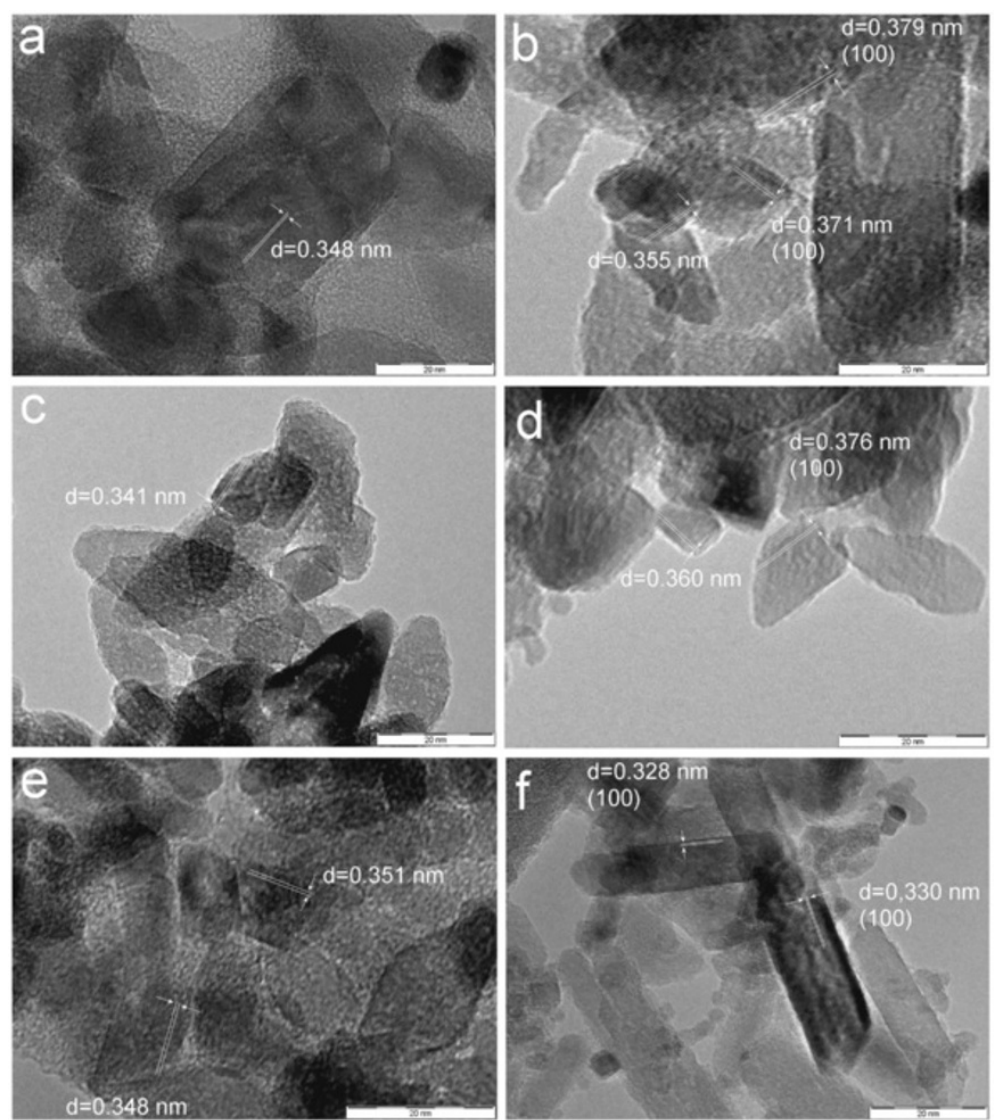

Figure 7 The TEM images of titanium oxides obtained with $\mathrm{Sn}^{2+}$ : a) TiSn2050, b) TiSn2100, c) TiSn2200, d) TiSn2300, e) TiSn2400 and f) TiSn2600.

Narva, its spectrum is shown in [64]). Photobleaching of soluble dyes is a commonly used test of novel catalysts $[1,6,22]$ irrespective of a complex nature of that reaction with some mechanistic aspects unclear [23].

According to the degradation pathway proposed by Zhao et al. [65], the main byproducts formed by the ozonation of azo-dye are organic acids, aldehydes, ketones, and carbon dioxide. Demirev and Nenov [66] suggested that the eventual degradation products of azo dye in the ozonation system would be acetic, formic and oxalic acids. The reaction pathway for the visible light-driven photocatalytic degradation of Orange II dye in aqueous $\mathrm{TiO}_{2}$ suspensions is schematically shown in [67].
On kinetics of heterogeneous photocatalysis for decomposition of model compounds such as dyes Orange II Langmiur-Hinshelwood equation [68] can be used:

$$
\mathrm{r}=-\mathrm{d}[\mathrm{OII}] / \mathrm{dt}=-\mathrm{k} \cdot \mathrm{r} \cdot \mathrm{K}[\mathrm{OII}] /(1+\mathrm{K} \cdot[\mathrm{OII}])
$$

where $r$ is the degree of dye mineralization, $k_{r}$ the rate constant, $\mathrm{t}$ the illumination time, $\mathrm{K}$ is the adsorption coefficient of the dye and [OII] is dye concentration. At very low concentration of the dye, in the validity of Lambert-Beer Law [69]:

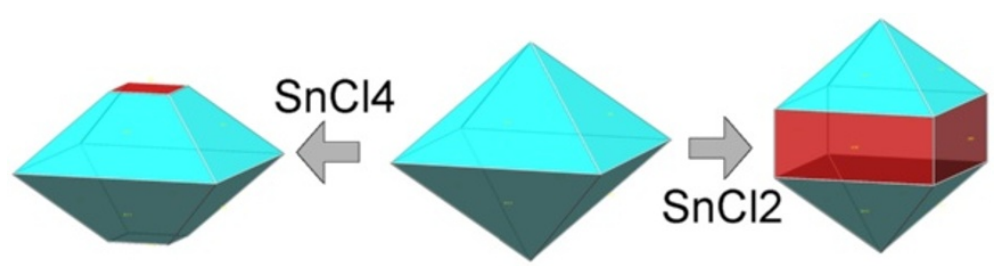

Figure 8 Changes of crystal morphology of anatase. 


$$
\mathrm{A}=\epsilon \cdot \mathrm{c} \cdot 1
$$

where $A$ is the absorbance, $c$ the dye concentration, $l$ the length of absorbent layer and $\epsilon$ is the molar absorption coefficient, it is possible to simplify equation (1) to the first order kinetic equation:

$$
\ln \left([\mathrm{OII}]_{\mathrm{o}}\right)+\mathrm{K}\left([\mathrm{OII}]-[\mathrm{OII}]_{\mathrm{o}}\right)=-\mathrm{k}_{\mathrm{r}} \cdot \mathrm{K} \cdot \mathrm{t}
$$

and after integration:

$$
[\mathrm{OII}]=[\mathrm{OII}]_{\mathrm{o}} \cdot \exp (-\mathrm{k} \cdot \mathrm{t}) ;\left(\mathrm{k}=\mathrm{k}_{\mathrm{r}} \cdot \mathrm{k}\right)
$$

For samples of $\mathrm{Sn}^{4+}$ doped titania at photocatalytic degradation under visible light different course of reaction has been observed. The kinetic curves showed a faster progress in its beginning.

The slowing of total photocatalytic decomposition may be due to heterogeneity of the sample, i.e. different rates of decomposition in various $\mathrm{TiO}_{2}$ crystalline modifications, anatase, brookite and rutile, or insufficient degradation of intermediates of photocatalytic reaction. Therefor the equation (5) was adapted to the following form:

$$
\begin{aligned}
& {[\mathrm{OII}]=[\mathrm{OII}]_{1} \cdot \operatorname{EXP}\left(-\mathrm{k}_{1} \cdot \mathrm{t}\right)+[\mathrm{OII}]_{2} \cdot \operatorname{EXP}\left(-\mathrm{k}_{2} \cdot \mathrm{t}\right) ;} \\
& {[\mathrm{OII}]_{0}=[\mathrm{OII}]_{1}+[\mathrm{OII}]_{2}+[\mathrm{OII}]_{3}}
\end{aligned}
$$

where $[\mathrm{OII}]_{0}$ is initial concentration of dye, $[\mathrm{OII}]_{1}$ is concentration of dye in time $\mathrm{t},[\mathrm{OII}]_{2}$ is concentration of reaction intermediates of photocatalytic degradation and $[\mathrm{OII}]_{3}$ is non-degradable residuum. In case if the intermediates decompose fast enough, then $k_{1}=k_{2}$ and the equation (5) goes to form (5).

The calculated degradation rate constants $\mathrm{k}$ for a reaction following first order model kinetics or $\mathrm{k}_{1}$ and $\mathrm{k}_{2}$ $\left(\mathrm{min}^{-1}\right)$ respectively, of degradation of Orange II dye at $365 \mathrm{~nm}$ (Black light) and $400 \mathrm{~nm}$ ("Warm White" light) are shown in Additional file 1: Table S5 and kinetics of degradation are presented in Figures 9 and 10.

The specific surface area of the catalysts increases with the increasing Sn content as a consequence of the presence of brookite and growing percentage of rutile with smaller particles than anatase; also decreasing particle size of anatase contributes to the surface area growth. As a consequence of all these phenomena, the specific surface area $\sigma(\mathrm{BET})$ of the catalysts is simply directly proportional to the total Sn content:

$$
\sigma(\mathrm{BET})=11.9 \cdot \mathrm{Sn}(\mathrm{wt} . \%)+120, \mathrm{r}^{2}=0.6372
$$

irrespectively of the form of Sn modification. To decipher the increase of the total available surface area of the catalyst and a possible specific effect of the Sn species, the rate coefficients were divided by the specific surface area of the catalysts for further data evaluation. For the reaction under UV irradiation there is a flat maximum of the specific reaction rate coefficient at $\mathrm{Sn}$ content between 4 and $10 \mathrm{wt} . \%$, irrespective of whether $\mathrm{SnCl}_{2}$ or $\mathrm{SnCl}_{4}$ was used for the synthesis. The samples marked TiSn410 and TiSn2300, which contains 5 wt.\% of Sn and $\sim 8$ wt.\% Sn show the highest photocatalytic activity.

The catalytic activity of the $\mathrm{SnCl}_{2}$ series under $>400 \mathrm{~nm}$ light is much lower than activity of the $\mathrm{SnCl}_{4}$ series, although both phase composition and particle size of the phase constituents in these two series are similar. The reaction rate coefficients normalized to the specific surface areas have a maximum at $\mathrm{Sn}$ contents between 0.7 and 5 wt.\% in the $\mathrm{SnCl}_{4}$ series, in which the Sn doping has an effect of remarkable "onset" of activity, then it is only weakly dependent on the actual Sn content: the surface-area normalized rate coefficients increased 25 times with respect to the pure titania. In the $\mathrm{SnCl}_{2}$ series the impact of Sn-modification is much less substantial: the Sn-doping increases the surface-area normalized rate coefficients only up to 5 times. This remarkable difference between the two series offers an opportunity to reveal the properties or features relevant for the photobleaching activity under $>400 \mathrm{~nm}$ light.

Two substantial differences between the $\mathrm{SnCl}_{2}$ and $\mathrm{SnCl}_{4}$ series are 1) heterogeneity of the phase composition and 2) Vis absorption features in the UV/Vis spectra. $\mathrm{SnCl}_{4}$ series is considerably more heterogeneous in terms of a bulk phase composition - most specimens contain all three titania polymorphs and additionally there is a considerable heterogeneity at $\mu \mathrm{m}$ spatial scale revealed by the Raman microanalysis (above). This apparent beneficial effect of heterogeneity at an intimate level of crystal contacts points to the seminal study by Vinodgopal and Kamat [1] on photocatalysis by physical mixtures of colloidal $\mathrm{SnO}_{2}$ and $\mathrm{TiO}_{2}$. There is no "tail" in the UV/Vis spectra of the Sn-doped titania in the region $400-500 \mathrm{~nm}$, but all these specimens have a distinct long-wavelength absorption $(>500 \mathrm{~nm})$. Probably the red shift of the absorption edge is not responsible for the catalytic activity improvement by $\mathrm{Sn}$, otherwise $\mathrm{SnCl}_{2}$ series would have been more active than $\mathrm{SnCl}_{4}$ series.

\section{Evaluation of Sn-titania obtained by "hydrogen peroxide route"}

There is no universal way to compare catalytic efficiency of titania specimens from published data, because practically each laboratory uses a different catalytic test. It is hence possible to evaluate only actual improvement in a given series of catalysts due to a given chemical 


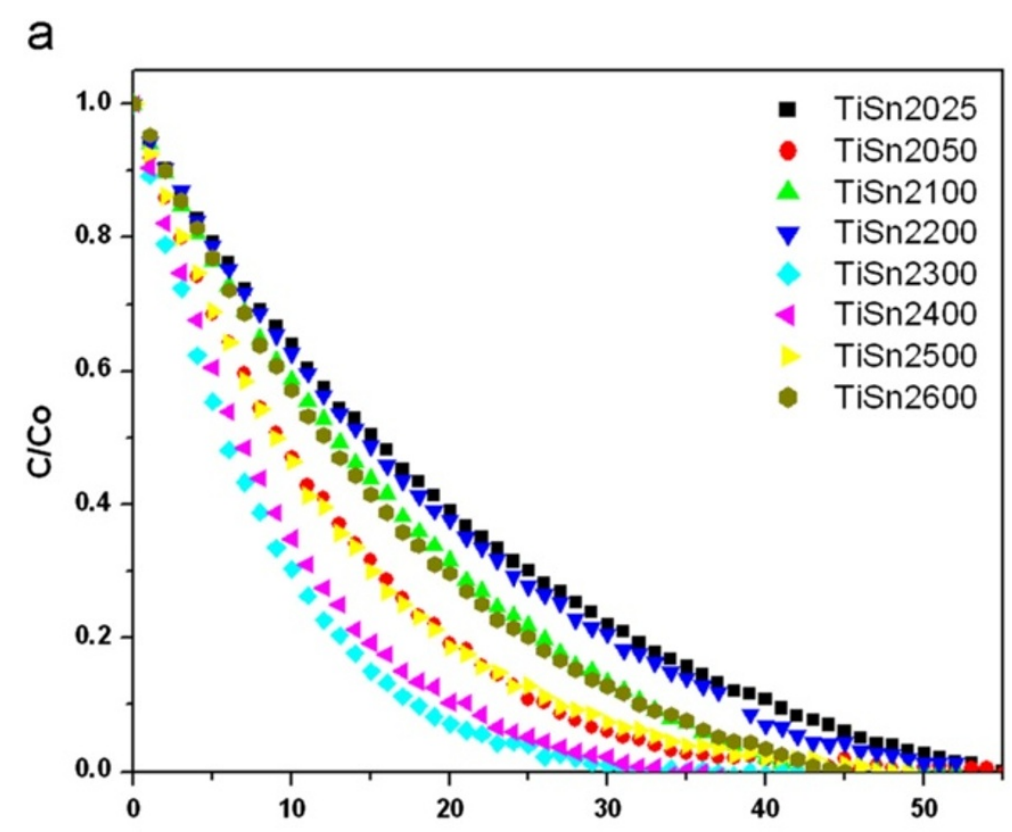

b

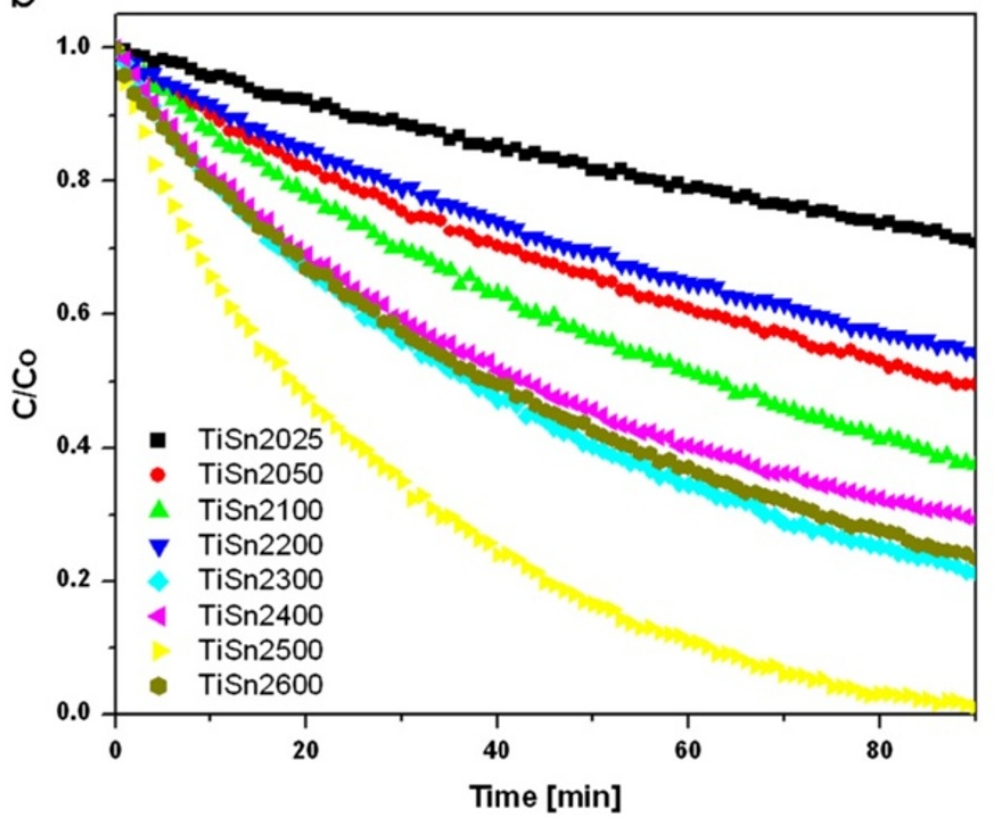

Figure 9 Orange II dye photobleaching on titanium oxides obtained with $\mathrm{Sn}^{2+}$ at wavelength a) $365 \mathrm{~nm}$ and b) $400 \mathrm{~nm}$.

modification to verify its real impact. Ohtani [23] correctly pointed to the lack of understanding of the detailed reaction mechanism of the azo dye photobleaching, but it still remains the simplest empirical way to handle large sample series with a reasonable effort and produces very useful insight into the measurable effect of the titania doping. For the catalysis under UV irradiation, novel materials are commonly compared with Degussa P25 titania, but for the Vis light there is no similar "reference". In our present study, the most efficient Sn-modified titania specimens obtained by the "hydrogen peroxide route" have the rate coefficients of the Orange II photobleaching under $>400 \mathrm{~nm}$ light by more than ten times larger initial rate than a control, non-doped titania. This is comparable to the best relative improvement yet reported for the Sn-modification [6]. Oropeza et al. [3] found that Sn-doping caused an onset of photocatalytic activity under $>420 \mathrm{~nm}$ irradiation 


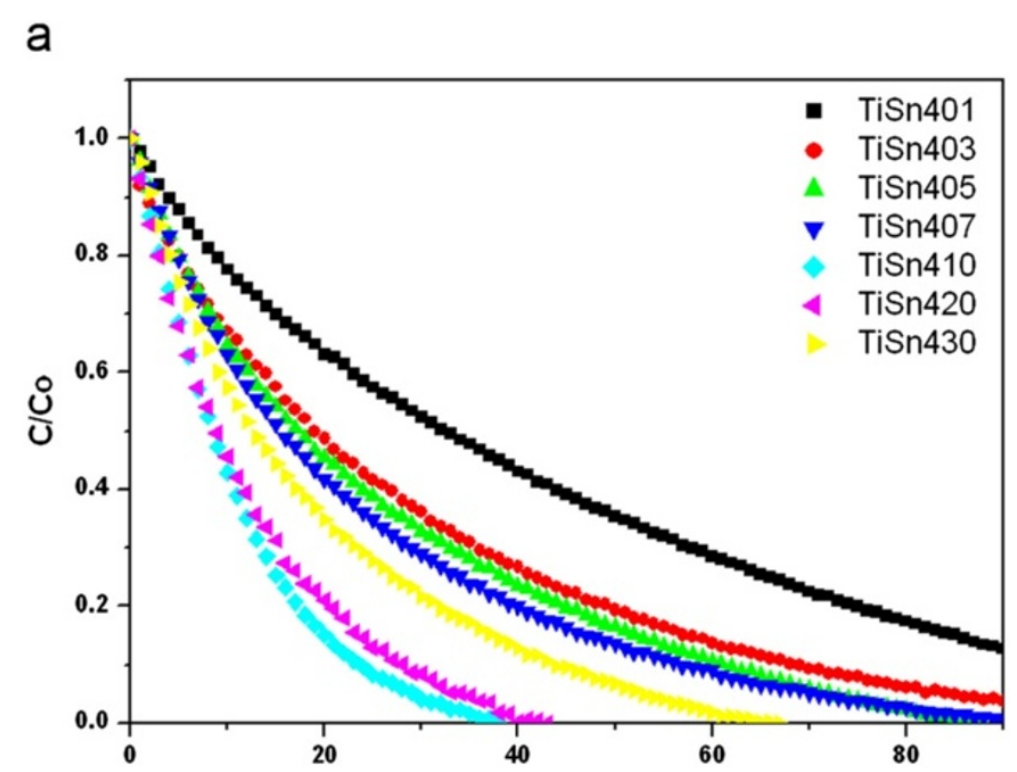

b

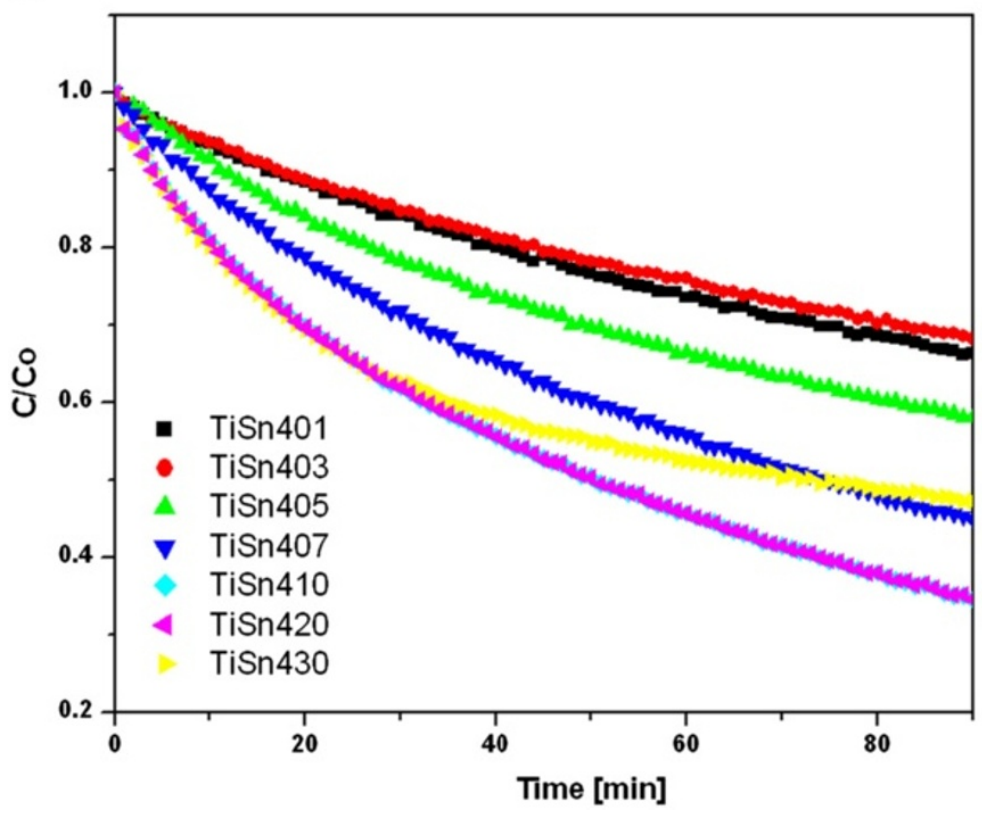

Figure 10 Orange II dye photobleaching on titanium oxides obtained with $\mathrm{Sn}^{4+}$ at wavelength a) $365 \mathrm{~nm}$ and b) $400 \mathrm{~nm}$.

in the comparison with the non-doped commercial titania catalysts and a better performance of the Sn-doped rutile than the N-doped titania. On the other hand, Cao et al. [4] and Zhao et al. [7] have found much less substantial effect of $\mathrm{Sn}$ (twofold increase in the rate coefficient). In the reports [70], [71] the effect of Sn addition was even smaller - obviously the Sn-modification is fully utilized only under certain synthesis conditions, actually including also our "hydrogen peroxide route". The best photocatalytic activity under $>400 \mathrm{~nm}$ light was achieved with the $\mathrm{Sn}^{4}$
${ }^{+}$-doped sample TiSn410, which has the rate coefficients $\mathrm{k}_{1}=0.0834 \mathrm{~min}^{-1}$ and $\mathrm{k}_{2}=0.00926 \mathrm{~min}^{-1}$. This result is comparable to or better than the best catalysts from the titania series obtained by modification using Mo [11], W [12], I [17], N [72] and B [72,73], which were also subjected to the same kinetic test as in this present study, the Orange II photobleaching at the same experimental setup.

The activity of the Sn-modified titania under the UV light can be compared with several previous titania specimens analyzed by the same kinetic test. The samples 
marked TiSn410 and TiSn2300, which contains $\sim 5$ wt.\% of $\mathrm{Sn}^{4+}$ and $\sim 8$ wt.\% of $\mathrm{Sn}^{2+}$, show the highest photocatalytic activity with the rate coefficients $0.0942 \mathrm{~min}^{-1}$ and $0.126 \mathrm{~min}^{-1}$, respectively, under UV light. The photobleaching by the tin-doped titanium oxides under UV is hence more than twice faster than by the Modoped titania $\left(\mathrm{k}=0.0461 \mathrm{~min}^{-1}\right)$ [11], W-doped titania $\left(\mathrm{k}=0.0617 \mathrm{~min}^{-1}\right)$ [12] and nearly the same as the Idoped titania $\left(\mathrm{k}=0.0851 \mathrm{~min}^{-1}\right)$ [17] prepared with the same synthesis method (the "hydrogen peroxide route"). The achieved reaction rate with Sn-doped titanium oxides is more than twice faster than with P25 under the same kinetic test $\left(\mathrm{k}=0.047 \mathrm{~min}^{-1}\right)$ [16].

\section{Experimental}

\section{Synthesis of tin-doped titanium oxides}

All chemicals used, titanium oxo-sulfate $\left(\mathrm{TiOSO}_{4}\right)$, tin (IV) chloride $\left(\mathrm{SnCl}_{4}\right)$, tin(II) chloride $\left(\mathrm{SnCl}_{2} \cdot 2 \mathrm{H}_{2} \mathrm{O}\right) \mathrm{am}$ monium hydroxide $\left(\mathrm{NH}_{4} \mathrm{OH}\right)$ and hydrogen peroxide $\left(\mathrm{H}_{2} \mathrm{O}_{2}\right)$ were of an analytical grade and were supplied by Sigma-Aldrich Ltd.

In a typical experiment, $100 \mathrm{~mL}$ of a $1.2 \mathrm{M}$ stock solution of titanium oxo-sulfate was diluted in $1 \mathrm{~L}$ of distilled water and hydrolyzed by slow addition of ammonium hydroxide solution (10\%) under continuous stirring at temperature of $0^{\circ} \mathrm{C}$ in ice bath, until the reaction mixture reached $\mathrm{pH} 8.0$.

At $0{ }^{\circ} \mathrm{C}$ does not proceed anatase or rutile nucleation and reaction resulted in amorphous phase $\mathrm{Ti}(\mathrm{OH})_{4}$, which can be easily dissolved by $\mathrm{H}_{2} \mathrm{O}_{2}$ to obtain right solution of titania peroxo complex, which gradually resulted to yellow gel. Precipitation above $0^{\circ} \mathrm{C}$ leads to formation of rutile or anatase nuclei and insufficient dissolution in titania peroxo-complex.

The obtained white precipitate was separated by filtration and washed with distilled water until it was free of sulfate ions (checked by the $\mathrm{BaCl}_{2}$ test). It was then mixed with $100 \mathrm{~mL}$ of $30 \%$ hydrogen peroxide solution that resulted in a homogeneous and transparent yellow gelatinous mass. That mass was subsequently mixed with defined amount of liquid tin(IV)chloride $\left(\mathrm{SnCl}_{4}\right)$ dosed with syringe, or solid tin(II) chloride $\left(\mathrm{SnCl}_{2} \cdot 2 \mathrm{H}_{2} \mathrm{O}\right)$; the actual ratios of the raw materials are listed in Tables 1 and 2 . The reaction mixture was then refluxed in a round-bottom flask in a heating mantle at $100^{\circ} \mathrm{C}$. On heating, the yellow gelatinous mass first turned dark orange and then it was gradually dissolved. During prolonged heating the solution color weakened and a yellowish white precipitate was formed. The refluxing was continued till the precipitate turned white, which lasted for $\sim 36$ hours. The obtained doped titanium oxides were air dried at $105^{\circ} \mathrm{C}$. Seven $\mathrm{Sn}^{4+}$-doped titanium oxides were obtained and denoted TiSn4XX, where XX is the input volume of $\mathrm{SnCl}_{4}$ (in $\mathrm{ml}$ ) and eight specimens obtained with $\mathrm{Sn}^{2+}$ were prepared and denoted TiSn2YYY, where YYY is the input weight of $\mathrm{SnCl}_{2} \cdot 2 \mathrm{H}_{2} \mathrm{O}$ (in grams).

\section{Conclusions}

The "hydrogen peroxide route" is an efficient and simple synthesis ("one-pot") method leading to Sn-modified titania photocatalysts remarkably active in the Orange II photobleaching under $>400 \mathrm{~nm}$ light. The most active catalysts were those consisting of two or three titania polymorphs, mainly anatase and rutile with minor brookite admixture. The Sn content decreases the particle size of titania polymorphs and increases the specific surface area of the catalysts, which is obviously beneficial for the photobleaching rate coefficients. The onset of the activity under $>400 \mathrm{~nm}$ light was particularly significant if $\mathrm{SnCl}_{4}$ was used in the synthesis; in that series more rutile was formed and the products had a more heterogeneous phase composition on the $\mu \mathrm{m}$ scale level. The formation of Sn-doped rutile and/or its presence in the catalyst seem to be responsible for the beneficial effect of the Sn doping. Additional feature specific to the titania specimens formed by the "hydrogen peroxide route" and possibly contributing to their improved activity is the oxygen over-stoichiometry due to the presence of $\mathrm{OH}^{-}$groups replacing $\mathrm{O}^{2-}$ groups of the titania. UV/Vis spectra of the most active catalysts had their absorption edges slightly red shifted and exhibited novel absorption bands at $>500 \mathrm{~nm}$. Both the used synthesis route and the Sn modification are promising ways to cheap and efficient photocatalysts for the Vis light activation.

\section{Methods}

\section{Characterization and analysis of solids}

Diffraction patterns were collected with diffractometer PANalytical X'Pert PRO with $\mathrm{Cu}$ X-ray tube and PIXcel detector [74]. A qualitative analysis was performed with the DiffracPlus Eva software package (Bruker AXS, Germany) using the JCPDS PDF-2 database [75]. For a quantitative analysis of XRD patterns we used DiffracPlus Topas (Bruker AXS, Germany, version 4.1) with structural models based on ICSD database [76]. This program permits to estimate the weight fractions of crystalline phases and mean coherence lengths by the Rietveld refinement.

The element composition of the catalysts was obtained by a conventional SEM/EDS analysis. The particle morphology was inspected by a transmission electron microscopy (TEM) and the crystal structure was analyzed by an electron diffraction using a $200 \mathrm{kV}$ TEM microscope JEOL 2010 F. A microscopic copper grid covered by a thin transparent carbon film was used as a specimen support. The photocatalysts were studied in a bright field and by the 
electron diffraction with a selecting aperture (SAED) mode at an acceleration voltage of $200 \mathrm{kV}$.

The surface areas of the photocatalysts were determined from nitrogen adsorption-desorption isotherms at a liquid nitrogen temperature using a Coulter SA3100 instrument with outgas $15 \mathrm{~min}$ at $150^{\circ} \mathrm{C}$. The BrunauerEmmett-Teller (BET) method was used for the surface area calculation [77], the pore size distribution (pore diameter, pore volume and micropore surface area of the titanium oxides) was determined by the Barrett-JoynerHalenda (BJH) method [78].

The Raman spectra were acquired with a DXR Raman microscope (Thermo Scientific) with $532 \mathrm{~nm}$ laser; 32 two-second scans were accumulated with $532 \mathrm{~nm}$ laser (3-4 mW) under 20-50x objective of an Olympus microscope. An analyzed spot size was 1-2 $\mu \mathrm{m}$. Infrared spectra were recorded by a Thermo-Nicolet Nexus 670 FT-IR spectrometer approximately in 4000-500 and 500$50 \mathrm{~cm}^{-1}$ with single-reflection horizontal accessory on $\mathrm{Si}$ crystal. The photocatalysts were mixed with $\mathrm{KBr}$ and pressed into pellets at ambient conditions and measured in the transmission mode.

An XPS apparatus was equipped with SPECS X-Ray XR50 (Al cathode $1486.6 \mathrm{eV}$ ) and a SPECS PHOIBOS 100 Hemispheric Analyzer with a 5-channel detector. A background pressure during the measurements was $<2 \cdot 10^{-}$ ${ }^{8}$ mbar. XPS survey-scan spectra were made at pass energy of $40 \mathrm{eV}$; the energy resolution was set to $0.5 \mathrm{eV}$, while individual high-resolution spectra were taken at pass energy of $10 \mathrm{eV}$ with $0.05 \mathrm{eV}$ energy steps. A software tool CasaXPS was used to fit high-resolution multi-component peaks. The proper surface-charge compensation was done by fitting $\mathrm{C}-\mathrm{C}, \mathrm{C}-\mathrm{H}$ component of $\mathrm{C} 1 \mathrm{~s}$ peak to reference binding energy $284.5 \mathrm{eV}$. The atomic concentration of compounds was evaluated with relative sensitivity factors (RSF) defined in a standard table of the CasaXPS software.

A Perkin Elmer Lambda 35 spectrometer equipped with a Labsphere RSAPE- 20 integration sphere with $\mathrm{BaSO}_{4}$ as a standard was used for the diffuse reflectance $\mathrm{UV} / \mathrm{Vis}$ spectra. The spectra were recorded in the diffuse reflectance mode and transformed to absorption spectra through the Kubelka-Munk function [64,79]:

$$
f(R)=(1-R)^{2} / 2 R
$$

where $f(R)$ is absorbance and $R$ is the reflectance of an "infinitely thick" layer of the solid.

\section{Photocatalytic activity test}

Photocatalytic activity of samples was assessed from the photobleaching kinetics of Orange II dye (sodium salt 4[(2-hydroxy-1-naphtenyl)azo]-benzene sulfonic acid) in $1000 \mathrm{ml}$ of aqueous slurries using a self-constructed photoreactor [21]. It consists of a stainless steel cover and a quartz tube with a fluorescent lamp by Narva with power $13 \mathrm{~W}$ and a light intensity $3.5 \mathrm{mWcm}^{2}$ (commercial name "Black Light", $365 \mathrm{~nm}$ ) and a Narva lamp with commercial name "Warm White" (emission spectrum $>400 \mathrm{~nm}$ ). The emission spectra of both light sources were shown in [73]. $0.5 \mathrm{~g}$ photocatalyst was dispersed for $10 \mathrm{~min}$ in an ultrasonic bath ( $300 \mathrm{~W}, 35 \mathrm{kHz}$ ) before use; actually that dispersion plays a crucial role in obtaining reproducible results of the kinetic tests. The $\mathrm{pH}$ of the resulting suspension was taken as the initial value for neutral conditions and under the experiment it was kept at a value of 7.0. Orange II dye solution was circulated by means of a membrane pump through a flow cell. The concentration of Orange II dye in the suspension was determined by measuring absorbance at $480 \mathrm{~nm}$ with Vis spectrophotometer ColorQuestXE. The suspension contained $5 \mathrm{mmol}$ of the dye at the beginning of the kinetic test, which is a substantial excess over what can be absorbed by the catalyst. Maximal adsorption of structurally similar azo dyes Orange $\mathrm{G}$ and Methyl Orange is $<10 \mu \mathrm{mol}$ per gram of P25 titania [22], hence in our experimental setup the azo dye amount exceeds the titania adsorption capacity by about two orders of magnitude. None of the two used light sources can degrade Orange II without a photocatalyst. The kinetic experiment started by switching on the light source after the spectral signal of the Orange II in the suspension reached a steady state; this actual initial signal was taken as a measure of the initial concentration of the dye. The sorption of the dye on the catalysts is hence irrelevant for the evaluation of the kinetic experiments.

\section{Additional file}

Additional file 1: Table S1. Cell parameters $a, b$ and $c$ of anatase, rutile and brookite doped with SnCl2. Table S2. Cell parameters $a, b$ and c of anatase, rutile and brookite doped with $\mathrm{SnCl} 4$. Figure S1. Infrared spectra of series samples a) $\mathrm{Sn} 4+$ doped $\mathrm{TiO}_{2}$ and b) $\mathrm{Sn} 2+$ doped $\mathrm{TiO} 2$. Table S3. Atomic concentrations of elements from XPS measurements. Table S4. Binding energies and FWHM of Sn 3d and Ti $2 p$ peaks. Figure S2. Pore area distribution of a) TiSn2025, b) TiSn2100, c) TiSn2200, d) TiSn2300, e) TiSn2500 and f) TiSn2600. Inset are hysteresis loops. Figure S3. Pore area distribution of a) TiSn401, b) TiSn403, c) TiSn405, d) TiSn410, e) TiSn420 and f) TiSn430. Inset are hysteresis loops. Figure S4. Selected Area Electron Diffraction (SAED) of sample a) TiSn2050 - anatase, b) TiSn2100 - anatase, c) TiSn2200 - anatase, d) TiSn2300 - brookite, e) TiSn2400 - anatase and f) TiSn2600 - rutile. Figure S5. Selected Area Electron Diffraction (SAED) of sample a) TiSn401 - anatase, b) TiSn405 - anatase, c) TiSn407 - anatase and brookite, d) TiSn410 - rutile, e) TiSn420 - rutile and f) TiSn430 - rutile. Figure S6. UV-VIS spectra of series samples a) Sn2+ doped TiO2 and b) Sn4+ doped $\mathrm{TiO} 2$. Figure S7. Band-gap energy of titanium oxides prepared in the presence of a) Sn2+ and b) Sn4t. Table S5. Rate constant k k, k1 and k2 of tin doped titania.

\section{Competing interests}

The authors declare that they have no competing interests.

\section{Authors' contributions}

VŠ was the main architect of this paper; he was responsible for the synthesis, catalytic tests and range of analytical methods. TMG performed Raman spectroscopy and contributed to the data interpretation. $\mathrm{JH}$ performed a lot 
of lab work and technical help with the manuscript. MK performed XPS analyses and most of their interpretations. All authors read and approved the final manuscript.

\section{Acknowledgements}

This work was supported by the RVO 61388980. The authors wish to thank to K. Šafářová of the Regional Centre of Advanced Technologies and Materials, Faculty of Science, Palacký University in Olomouc for providing the HRTEM measurements and P. Bezdička and M. Maříková of the Institute of Inorganic Chemistry AS CR, v.v.i., Řež for providing the XRD and IR measurements, respectively. We also acknowledge a technical help by $P$. Matysová (Brandýs n.L., Czech Republic).

\section{Author details}

${ }^{1}$ Department of Solid State Chemistry and Analytical Laboratory, Institute of Inorganic Chemistry AS CR v.vi.., 250 68, Rež, Czech Republic. ${ }^{2}$ Faculty of the Environment, J.E. Purkyně University, Králova Výšina 7, 400 96, Ústí nad Labem, Czech Republic. ${ }^{3}$ Department of Physics, Faculty of Science, J.E. Purkyně University, České mládeže 8, 400 96, Ústí nad Labem, Czech Republic.

Received: 29 August 2012 Accepted: 25 September 2012

Published: 5 October 2012

\section{References}

1. Vinodgopal K, Kamat PV: Enhanced rates of photocatalytic degradation of an azo-dye using $\mathrm{SnO}_{2} / \mathrm{TiO}_{2}$ coupled semiconductor thin-films. Environ Sci Technol 1995, 29(3):841-845.

2. Lin J, Yu JC, Lo D, Lam SK: Photocatalytic activity of rutile $\mathrm{Ti}_{1-x} \mathrm{Sn}_{\mathrm{x}} \mathrm{O}_{2}$ solid solutions. J Catal 1999, 183(2):368-372.

3. Oropeza FE, Davies B, Palgrave RG, Egdell RG: Electronic basis of visible region activity in high area $\mathrm{Sn}$-doped rutile $\mathrm{TiO}_{2}$ photocatalysts. Phys Chem Chem Phys 2011, 13(17):7882-7891.

4. Cao YA, Yang WS, Zhang WF, Liu GZ, Yue PL: Improved photocatalytic activity of $\mathrm{Sn}^{4+}$ doped $\mathrm{TiO}_{2}$ nanoparticulate films prepared by plasmaenhanced chemical vapor deposition. New Journal of Chemistry 2004, 28(2):218-222

5. Sayilkan F, Asiltuerk M, Tatar P, Kiraz N, Sener S, Arpac E, Sayilkan H: Photocatalytic performance of $\mathrm{Sn}$-doped $\mathrm{TiO}_{2}$ nanostructured thin films for photocatalytic degradation of malachite green dye under UV and VIS-lights. Mater Res Bull 2008, 43(1):127-134.

6. Boppana VBR, Lobo RF: Photocatalytic degradation of organic molecules on mesoporous visible-light-active Sn(II)-doped titania. J Catal 2011, 281(1):156-168.

7. Zhao Y, Liu J, Shi LY, Yuan SA, Fang JH, Wang ZY, Zhang MH: Surfactantfree synthesis uniform $\mathrm{Ti}_{1-\mathrm{x}} \mathrm{Sn}_{\mathrm{x}} \mathrm{O}_{2}$ nanocrystal colloids and their photocatalytic performance. App/ Catal B-Environ 2010, 100(1-2):68-76.

8. Hirano M, Dozono $\mathrm{H}$, Kono $\mathrm{T}$ : Hydrothermal synthesis and properties of solid solutions and composite nanoparticles in the $\mathrm{TiO}_{2}-\mathrm{SnO}_{2}$ system. Mater Res Bull 2011, 46(9):1384-1390.

9. Liu J, Zhao Y, Shi LY, Yuan SA, Fang JH, Wang ZY, Zhang MH: Solvothermal Synthesis of Crystalline Phase and Shape Controlled $\mathrm{Sn}^{4+}$-Doped $\mathrm{TiO}_{2}$ Nanocrystals: Effects of Reaction Solvent. ACS Applied Materials \& Interfaces 2011, 3(4):1261-1268.

10. Cerny Z, Stengl V: Method of production photocatalytic active monodispersed titanium(IV) oxide. CZ 301006 B6, Czech Rep. 2009.

11. Stengl V, Bakardjieva S: Molybdenum-Doped Anatase and Its Extraordinary Photocatalytic Activity in the Degradation of Orange II in the UV and vis Regions. J Phys Chem C 2010, 114(45):19308-19317.

12. StengI V, Velicka J, Marikova M, Matys Grygar T: New Generation Photocatalysts: How Tungsten Influences the Nanostructure and Photocatalytic Activity of $\mathrm{TiO}_{2}$ in the UV and Visible Regions. ACS Applied Materials \& Interfaces 2011, 3(10):4014-4023.

13. Bakardjieva S, Subrt J, StengI V, Perez-Maqueda LA, Alario-Franco MA: Characterization of photocatylitically active TiO2 by electron microscopy: Proceedings of the 5th Multinational Congress on Electron Microscopy. Lecce, Italy: Rinton Press, Inc, 565 Edmund Terrace, Princeton, NJ 07652 USA; 2001:463-464. Conference: 5th Multinational Congress on Electron Microscopy.

14. StengI V, Subrt J, Bezdicka P, Marikova M, Bakardjieva S: Homogeneous precipitation with urea - An easy process for making spherical hydrous metal oxides. In Conference: 5th International Conference on Solid State Chemistry, Solid State Phenomena, Volume: 90-91. Edited by Sajgalik P, Drabik M, Varga S. Bratislava, Slovakia: Trans Tech Publications Ltd, Brandrain 6, CH-8707 Zurich-Uetikon, Switzerland; 2003:121-126. Date: Jul 07-12, 200, Solid State Chemistry V.

15. Krysa J, Keppert M, Jirkovsky J, StengI V, Subrt J: The effect of thermal treatment on the properties of $\mathrm{TiO}_{2}$ photocatalyst. Mater Chem Phys 2004, 86(2-3):333-339.

16. Stengl V, Bakardjieva S, Murafa N: Preparation and photocatalytic activity of rare earth doped $\mathrm{TiO}_{2}$ nanoparticles. Mater Chem Phys 2009, 114(1):217-226.

17. Václav Štengl, Tomáš Matys Grygar: The Simplest Way to lodine-Doped Anatase for Photocatalysts Activated by Visible Light. International Journal of Photoenergy 2011, 2011(Article ID 685935):13. doi:10.1155/2011/685935.

18. Stengl V, Bakardjieva S, Bludska J: Se and Te-modified titania for photocatalytic applications. J Mater Sci 2011, 46(10):3523-3536

19. Sui RH, Young JL, Berlinguette CP: Sol-gel synthesis of linear Sn-doped $\mathrm{TiO}_{2}$ nanostructures. J Mater Chem 2010, 20(3):498-503.

20. Li DR, Sun LN, Hu CW: Simple Preparation of the Photocatalyst of $\mathrm{Sn}^{2+}$-doped Titania. Chin Chem Lett 2006, 17(8):1089-1092.

21. Stengl V, Houskova V, Bakardjieva S, Murafa N, Havlin V: Optically Transparent Titanium Dioxide Particles Incorporated in Poly (hydroxyethyl methacrylate) Thin Layers. J Phys Chem C 2008, 112(50):19979-19985.

22. Lachheb H, Puzenat E, Houas A, Ksibi M, Elaloui E, Guillard C, et al: Photocatalytic degradation of various types of dyes (Alizarin S, Crocein Orange G, Methyl Red, Congo Red, Methylene Blue) in water by UV-irradiated titania. App/ Catal Environ 2002, 39(1):75-90.

23. Ohtani B: Photocatalysis A, to Z-What we know and what we do not know in a scientific sense. Journal of Photochemistry and Photobiology C: Photochemistry Reviews 2010, 11(4):157-178.

24. Nag M, Basak P, Manorama SV: Low-temperature hydrothermal synthesis of phase-pure rutile titania nanocrystals: Time temperature tuning of morphology and photocatalytic activity. Mater Res Bull 2007, 42(9):1691-1704.

25. Aruna ST, Tirosh S, Zaban A: Nanosize rutile titania particle synthesis a hydrothermal method without mineralizers. J Mater Chem 2000, 10(10):2388-2391.

26. Subrt J, Stengl V: Preparation of acicular alpha- $\mathrm{Fe}_{2} \mathrm{O}_{3}$ (Hematite). J Mater Sci Lett 1993, 12(11):836-838.

27. Kumar KNP, Keizer K, Burggraaf AJ: Stabilization of the Porous Texture of Nanostructured Titania by Avoiding a Phase-Transformation. J Mater Sci Lett 1994, 13(1):59-61.

28. Cheng HM, Ma JM, Zhao ZG, Qi LM: Hydrothermal preparation of uniform nanosize rutile and anatase particles. Chem Mater 1995, 7(4):663-671.

29. Li JG, Ishigaki T, Sun XD: Anatase, brookite, and rutile nanocrystals via redox reactions under mild hydrothermal conditions: Phase-selective synthesis and physicochemical properties. J Phys Chem C 2007, 111(13):4969-4976.

30. Liu G, Yang HG, Sun CH, Cheng LN, Wang LZ, Lu GQ, Cheng HM: Titania polymorphs derived from crystalline titanium diboride. CrystEngComm 2009, 11(12):2677-2682.

31. Pottier A, Chaneac C, Tronc E, Mazerolles L, Jolivet JP: Synthesis of brookite $\mathrm{TiO}_{2}$ nanoparticles by thermolysis of $\mathrm{TiCl}_{4}$ in strongly acidic aqueous media. J Mater Chem 2001, 11(4):1116-1121.

32. Kobayashi M, Petrykin V, Tomita K, Kakihana M: Hydrothermal synthesis of brookite-type titanium dioxide with snowflake-like nanostructures using a water-soluble citratoperoxotitanate complex. J Cryst Growth 2011, 337(1):30-37.

33. Zhao J, Wang Z, Wang L, Yang H, Zhao M: Effect of Nuclei on the Formation of Rutile Titania. J Mater Sci Lett 1998, 17(22):1867-1869.

34. Stengl V, Kralova D: Photoactivity of brookite-rutile $\mathrm{TiO}_{2}$ nanocrystalline mixtures obtained by heat treatment of hydrothermally prepared brookite. Mater Chem Phys 2011, 129(3):794-801.

35. Pullar RC, Penn SJ, Wang X, Reaney IM, Alford NM: Dielectric loss caused by oxygen vacancies in titania ceramics. J Eur Ceram Soc 2009, 29(3):419-424

36. Wu S, Wang G, Wang S, Liu D: Effect of $\mathrm{Sn}^{4+}$ B-Site Substitution on the Microstructure and Dielectric Properties of $\mathrm{Ba}\left(\mathrm{Mg}_{1 / 3} \mathrm{Ta}_{2 / 3}\right) \mathrm{O}_{3}$ Microwave Ceramics. J Mater Sci Technol 2005, 21(5):773-775.

37. Cox H, Stace AJ: Molecular View of the Anomalous Acidities of $\mathrm{Sn}^{2+}, \mathrm{Pb}^{2+}$ and $\mathrm{Hg}^{2+}$. J Am Chem Soc 2004, 126(12):3939-3947. 
38. Shi ZM, Yan L, Jin LN, Lu XM, Zhao G: The phase transformation behaviors of Sn2 +-doped Titania gels. J Non-Cryst Solids 2007, 353(22-23):2171-2178.

39. Krishnamurti D: The Raman spectrum of rutile. Proceeding of Indian Academy of Sciences Section A. Indian Academy of Sciences 1962, 55:290-299.

40. Tompsett GA, Bowmaker GA, Cooney RP, Metson JB, Rodgers KA, Seakins JM: The Raman spectrum of brookite, $\mathrm{TiO}_{2}(\mathrm{PBCA}, \mathrm{Z}=8)$. Journal of Raman Spectroscopy 1995, 26(1):57-62.

41. Swamy V, Muddle BC, Dai Q: Size-dependent modifications of the Raman spectrum of rutile $\mathrm{TiO}_{2}$. Appl Phys Lett 2006, 89(16).

42. Choi HC, Jung YM, Kim SB: Size effects in the Raman spectra of $\mathrm{TiO}_{2}$ nanoparticles. Vib Spectrosc 2005, 37(1):33-38.

43. Chen L-C, Tsai F-R, Fang S-H, Ho Y-C: Properties of sol-gel $\mathrm{SnO}_{2} / \mathrm{TiO}_{2}$ electrodes and their photoelectrocatalytic activities under UV and visible light illumination. Electrochim Acta 2009, 54(4):1304-1311.

44. Kelly S, Pollak FH, Tomkiewicz M: Raman spectroscopy as a morphological probe for $\mathrm{TiO}_{2}$ aerogels. Journal of Physical Chemistry B 1997, 101(14):2730-2734.

45. Kamisaka H, Suenaga T, Nakamura H, Yamashita K: DFT-Based Theoretical Calculations of $\mathrm{Nb}$ - and W-Doped Anatase $\mathrm{TiO}_{2}$ Complex Formation between W Dopants and Oxygen Vacancies. J Phys Chem C 2010, 114(29):12777-12783.

46. Shao GS, Zhang XJ, Yuan ZY: Preparation and photocatalytic activity of hierarchically mesoporous-macroporous $\mathrm{TiO}_{2-x} \mathrm{~N}_{\mathrm{x}}$. Appl Catal Environ 2008, 82(3-4):208-218.

47. Connor PA, Dobson KD, McQuillan AJ: Infrared spectroscopy of the $\mathrm{TiO}_{2}$ / aqueous solution interface. Langmuir 1999, 15(7):2402-2408.

48. Jere GV, Patel CC: Infrared absorption studies on peroxy titanium sulphate. Canadian Journal of Chemistry-Revue Canadienne De Chimie 1962 40(8):1576-1578

49. Nakamura R, Imanishi A, Murakoshi $K$, Nakato $Y$ : In situ FTIR studies of primary intermediates of photocatalytic reactions on nanocrystalline $\mathrm{TiO}_{2}$ films in contact with aqueous solutions. J Am Chem Soc 2003, 125(24):7443-7450.

50. Lin W, Zhang YF, Li Y, Ding KN, Li JQ, Xu YJ: Structural characterizations and electronic properties of Ti-doped $\mathrm{SnO}_{2}$ (110) surface: A firstprinciples study. J Chem Phys 2006, 124(5):054704.

51. Cao YQ, He T, Zhao LS, Wang EJ, Yang WS, Cao YA: Structure and Phase Transition Behavior of Sn4+-Doped TiO2 Nanoparticles. J Phys Chem C 2009, 113(42):18121-18124.

52. Kim KS, Winograd N: Charge-transfer shake-up satellites in X-ray photoelectron-spectra of cations and anions of $\mathrm{SrTiO}_{3}, \mathrm{TiO}_{2}$ and $\mathrm{Sc}_{2} \mathrm{O}_{3}$. Chem Phys Lett 1975, 31(2):312-317

53. Ayouchi R, Martin F, Barrado JRR, Martos M, Morales J, Sanchez L: Use of amorphous tin-oxide films obtained by spray pyrolysis as electrodes in lithium batteries. Journal of Power Sources 2000, 87(1-2):106-111.

54. Song SK, Cho JS, Choi WK, Jung HJ, Choi DS, Lee JY, Baik HK, Koh SK: Structure and gas-sensing characteristics of undoped tin oxide thin films fabricated by ion-assisted deposition. Sensors and Actuators B-Chemical 1998, 46(1):42-49.

55. Tsunekawa S, Kang J, Asami K, Kawazoe Y, Kasuya A: Size and time dependences of the valence states of $\mathrm{Sn}$ ions in amphoteric tin oxide nanoparticles. App/ Surf Sci 2002, 201(1-4):69-74.

56. Barreca D, Garon S, Tondello E, Zanella P: $\mathrm{SnO}_{2}$ Nanocrystalline Thin Films by XPS. Surface Science Spectra 2000, 7(2):81-85.

57. Strýhal Z, Stofík M, Malý J, Pavlík J: Periodically arranged tin and tin oxide nanoparticles. Proceedings of ICTF 14 \& RSD. Gent: University of Gent; 2008:306-310.

58. de Boer JA: The Shape of capillaries. In The Structure and Properties of Porous Materials. Edited by Everett DH, Stone FS. London: Butterworths; 1958:68-92.

59. Wen $\mathrm{PH}$, Itoh $\mathrm{H}$, Tang WP, Feng Q: Single nanocrystals of anatase-type $\mathrm{TiO}_{2}$ prepared from layered titanate nanosheets: Formation mechanism and characterization of surface properties. Langmuir 2007, 23(23):11782-11790

60. Pan J, Liu G, Lu GM, Cheng HM: On the True Photoreactivity Order of $001\},\{010\}$, and $\{101$ Facets of Anatase TiO2 Crystals. Angew Chem Int Ed 2011, 50(9):2133-2137.

61. Liu G, Yu JC, Lu GQ, Cheng H-M: Crystal facet engineering of semiconductor photocatalysts: motivations, advances and unique properties. Chem Commun 2011, 47(24):6763-6783.
62. Kumar SG, Devi LG: Review on Modified $\mathrm{TiO}_{2}$ Photocatalysis under UV/ Visible Light: Selected Results and Related Mechanisms on Interfacial Charge Carrier Transfer Dynamics. J Phys Chem A 2011, 115(46):13211-13241.

63. Fang WQ, Gong X-Q, Yang HG: On the Unusual Properties of Anatase $\mathrm{TiO}_{2}$ Exposed by Highly Reactive Facets. J Phys Chem Lett 2011, 2(7):725-734.

64. Orel ZC, Gunde MK, Orel B: Application of the Kubelka-Munk theory for the determination of the optical properties of solar absorbing paints. Progress in Organic Coatings 1997, 30(1-2):59-66.

65. Zhao WR, Shi HX, Wang DH: Ozonation of Cationic Red X-GRL in aqueous solution: degradation and mechanism. Chemosphere 2004, 57(9):1189-1199.

66. Demirev A, Nenov V: Ozonation of two acidic azo dyes with different substituents. Ozone Sci Eng 2005, 27(6):475-485.

67. Stylidi M, Kondarides DI, Verykios XE: Visible light-induced photocatalytic degradation of Acid Orange 7 in aqueous $\mathrm{TiO}_{2}$ suspensions. App/ Catal Environ 2004, 47(3):189-201.

68. $\mathrm{Mu} \mathrm{Y}, \mathrm{Yu} \mathrm{HQ}$, Zheng JC, Zhang SJ: $\mathrm{TiO}_{2}$-mediated photocatalytic degradation of Orange II with the presence of $\mathrm{Mn}^{2+}$ in solution. Journal of Photochemistry and Photobiology A-Chemistry 2004, 163(3):311-316.

69. Yu QL, Ballari MM, Brouwers HJH: Indoor air purification using heterogeneous photocatalytic oxidation. Part II: Kinetic study. Applied Catalysis B-Environmental 2010, 99(1-2):58-65.

70. Ischia M, Campostrini R, Lutterotti L, Garcia-Lopez E, Palmisano L, Schiavello M, Pirillo F, Molinari R: Synthesis, characterization and photocatalytic activity of $\mathrm{TiO}_{2}$ powders prepared under different gelling and pressure conditions. Journal of Sol-gel Science and Technology 2005, 33(2):201-213.

71. Fresno F, Guillard C, Coronado JM, Chovelon JM, Tudela D, Soria J, Herrmann JM: Photocatalytic degradation of a sulfonylurea herbicide over pure and tin-doped $\mathrm{TiO}_{2}$ photocatalysts. Journal of Photochemistry and Photobiology A-Chemistry 2005, 173(1):13-20.

72. Henych J: Titanium Oxide and Its Photocatalytic Activity (in Czech). Thesis: J.E. Purkyně University in Ústí nad Labem; 2010.

73. Stengl V, Houskova V, Bakardjieva S, Murafa N: Photocatalytic Activity of Boron-Modified Titania under UV and Visible-Light Illumination. ACS Applied Materials \& Interfaces 2010, 2(2):575-580.

74. Stengl V, Matys Grygar T, Oplustil F, Nemec T: Sulphur mustard degradation on zirconium doped Ti-Fe oxides. J Hazard Mater 2011, 192(3):1491-1504.

75. Jcpds PDF: Release 50. Newtown Square: International Centre for Diffraction Data; 2000.

76. ICSD Database FIZ Karlsruhe G.

77. Brunauer S, Emmett PH, Teller E: Adsorption of gases in multimolecular layers. J Am Chem Soc 1938, 60:309-319.

78. Barrett EP, Joyner LG, Halenda PP: The determination of pore volume and area distributions in porous substances. 1. Computations from nitrogen isotherms. J Am Chem Soc 1951, 73(1):373-380.

79. Christy AA, Kvalheim OM, Velapoldi RA: Quantitative-analysis in diffuse-reflectance spectrometry - a modified Kubelka-Munk equation. Vib Spectrosc 1995, 9(1):19-27.

doi:10.1186/1752-153X-6-113

Cite this article as: Štengl et al:: Hydrogen peroxide route to Sn-doped titania photocatalysts. Chemistry Central Journal 2012 6:113.

\section{Publish with ChemistryCentral and every scientist can read your work free of charge \\ "Open access provides opportunities to our colleagues in other parts of the globe, by allowing anyone to view the content free of charge." W. Jeffery Hurst, The Hershey Company.}

- available free of charge to the entire scientific community

- peer reviewed and published immediately upon acceptance

- cited in PubMed and archived on PubMed Central

- yours - you keep the copyright

Submit your manuscript here:

http://www.chemistrycentral.com/manuscript/
()

ChemistryCentral 